Supporting Information for

\title{
Nanochannels of Covalent Organic Frameworks for Chiral Selective Transmembrane Transport of Amino Acids
}

\author{
Chen Yuan, ${ }^{\dagger}$ Xiaowei Wu,${ }^{\dagger}$ Rui Gao,${ }^{\dagger}$ Xing Han,${ }^{\dagger}$ Yan Liu,${ }^{\dagger}$ Yitao Long, $,{ }^{*}, \underset{\text { and }}{ }$ Yong Cui ${ }^{*},{ }^{\dagger}$ \\ †School of Chemistry and Chemical Engineering and State Key Laboratory of Metal Matrix \\ Composites, Shanghai Jiao Tong University, Shanghai 200240, China \\ * School of Chemistry and Molecular Engineering, East China University of Science and \\ Technology, Shanghai 200237, China \\ Email:yitaolong@nju.edu.cn; yongcui@sjtu.edu.cn
}

\section{Table of Content}

1. Materials and general procedures........................................... 2

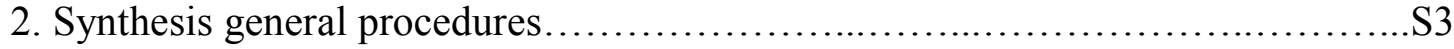

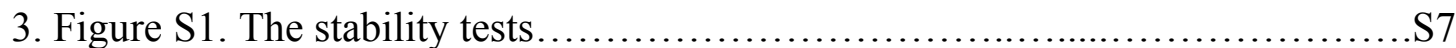

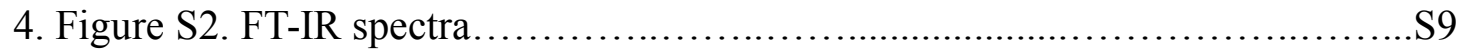

5. Figure S3. Solid-state ${ }^{13} \mathrm{C}$ NMR spectra ......................................... 10

6. Figure S4. SEM images of COFs .................................................... 11

7. Figure S5. TEM images of COFs................................................ 12

8. Figures S6-S9. Structural modeling and PXRD analysis of the COFs............S13

9. Figures S10-S12. Characterization of CD-COFs..................................S16

10. Figures S13-14. Optic photos and SEM of COF MMMs......................S20

11. Figures S15-S16. Ionic current measurement..................................S21

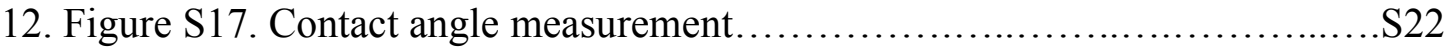

13. Tables S1-S2. Surface zeta potential measurements.........................S23

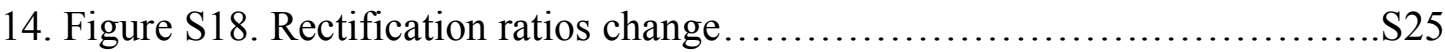

15. Figures S19-S21. I- $V$ characteristics of COF MMMs .......................S26

16. Figures S22-S28. Characterization of CD-COF-1' ..........................S29

17. Figures S29-S30. The reproducibility of MMMs.............................S35

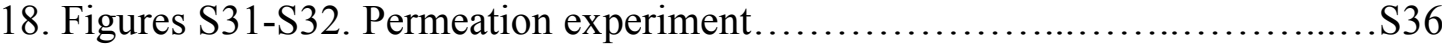

19. Tables S3-S4. Fractional atomic coordinates for the unit cell..................S38

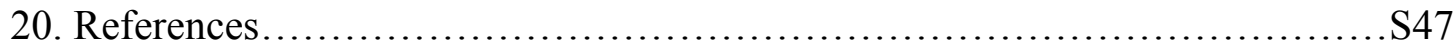




\section{Materials and general procedures.}

All the chemicals are commercially available, and used without further purification. All solvents were dried and distilled according to standard laboratory methods. The IR (KBr pellet) spectra were recorded on a Spectrum 100, Perkin Elmer, Inc. Powder X-ray diffraction data (PXRD) were collected on a Bruker D8 Advance diffractometer using $\mathrm{Cu} \mathrm{K} \alpha$ radiation. Thermogravimetric analyses (TGA) were carried out in an air atmosphere with a heating rate of $5{ }^{\circ} \mathrm{C} / \mathrm{min}$ on a Q5000IR, TA Instruments, USA. Scanning Electron Microscopy (SEM) images were performed on a Nova NanoSEM 450, FEI. Transmission Electron Microscopy (TEM) images were obtained with a JEM-2100, JEOL. ${ }^{1} \mathrm{H}$ and ${ }^{13} \mathrm{C}$ NMR experiments were carried out on a MERCURY plus 400 spectrometer operating at resonance frequencies of $400 \mathrm{MHz}$. Solid ${ }^{13} \mathrm{C}$ NMR experiments were carried out on an AVANCE III HD 400 Bruker BioSpin Corp. The porous properties of the covalent organic frameworks (COFs) were investigated by nitrogen adsorption and desorption at $77.3 \mathrm{~K}$ using ASAP 2020, Micromeritics Instrument Corp, USA. The pore-size-distribution curves were obtained from the adsorption branches using non-local density functional theory (NLDFT) method. Before the adsorption measurement, the samples were activated at $120{ }^{\circ} \mathrm{C}$ under vacuum $\left(<10^{-3}\right.$ torr $)$ for $12 \mathrm{~h}$. Ion currents were measured by an Axon Axopatch 200B Capacitor Feedback Patch Clamp Amplifier (Molecular Devices, Union City, CA, US). Ion currents data were acquired by using a DigiData 1550A converter and a PC running PClamp 10.6 (Axon Instruments, Forest City, CA, USA). Contact angles were measured using a DSA 30 machine (Kruss, Germany) contact-angle system at ambient temperature and saturated humidity. Zeta potentials were measured using Zetasizer Nano ZS ZEN3600 machine (Malvern Instruments, UK) and Zetasizer Nano ZS90/ZS machine (Malvern Instruments, UK). Analytical high performance liquid chromatography (HPLC) experiments were performed on a Shimadzu HPLC system (Shimadzu Corporation, Kyoto, Japan) with UV detection at $200 \mathrm{~nm}$. Optical resolution column (Crownpak CR(-), Daicel Chemical Industries, Ltd., Japan) and perchloric acid ( $\mathrm{pH} 1.0-2.0)$ as mobile phase are used. 


\section{Synthesis and general procedures.}

2.1 Synthesis of COF-1:

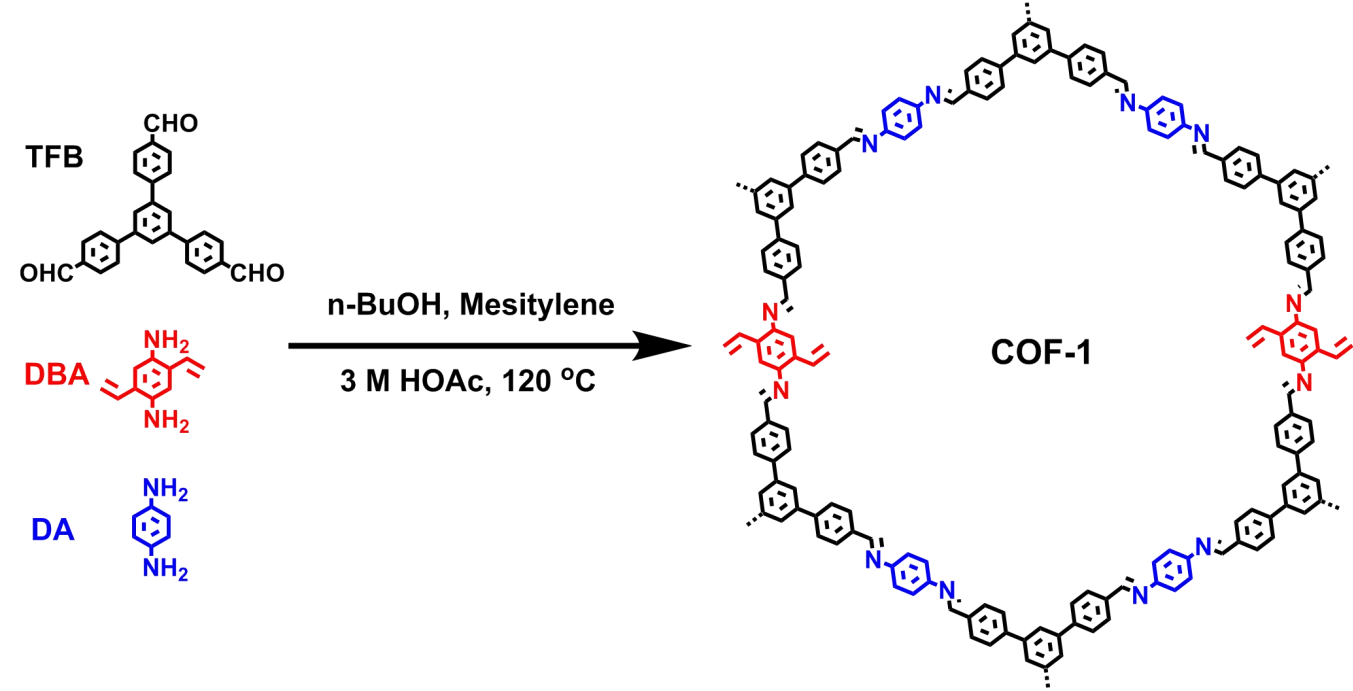

2,5-divinylbenzene-1,4-diamine was synthesized according to the published procedure. ${ }^{1}$

A $10 \mathrm{~mL}$ Schlenk tube was charged with 1,3,5-tris(4-formylphenyl)benzene (TFB) (25 mg, $0.064 \mathrm{mmol}), 2,5$-divinylbenzene-1,4-diamine (DBA) $(5.1 \mathrm{mg}, 0.032 \mathrm{mmol}$ ), p-phenylenediamine (DA) (6.9 mg, $0.064 \mathrm{mmol}), \mathrm{n}-\mathrm{BuOH}(0.75 \mathrm{~mL})$ and mesitylene $(0.75 \mathrm{~mL})$. The resulting mixture was sonicated for $10 \mathrm{~min} .3 \mathrm{M}$ acetic acid $(0.2 \mathrm{~mL})$ was then added to the solution, and the Schlenk tube was flash frozen at $77 \mathrm{~K}$ using the liquid nitrogen bath, evacuated and sealed by Teflon valve. Upon warming to room temperature, the Schlenk tube was heated at $120{ }^{\circ} \mathrm{C}$ for 5 days. And the yellow solid was isolated by centrifugation and washed with THF $(3 \times 10 \mathrm{~mL})$ and $\mathrm{Et}_{2} \mathrm{O}(3 \times$ $10 \mathrm{~mL}$ ). Further purification of COF-1 was carried out by Soxhlet extraction in THF for $24 \mathrm{~h}$. The powder was dried at $60{ }^{\circ} \mathrm{C}$ under vacuum overnight to afford $\mathrm{COF}-1$ as yellow powder. Yield: (32 mg, 86\%). 
2.2 Synthesis of COF-1':

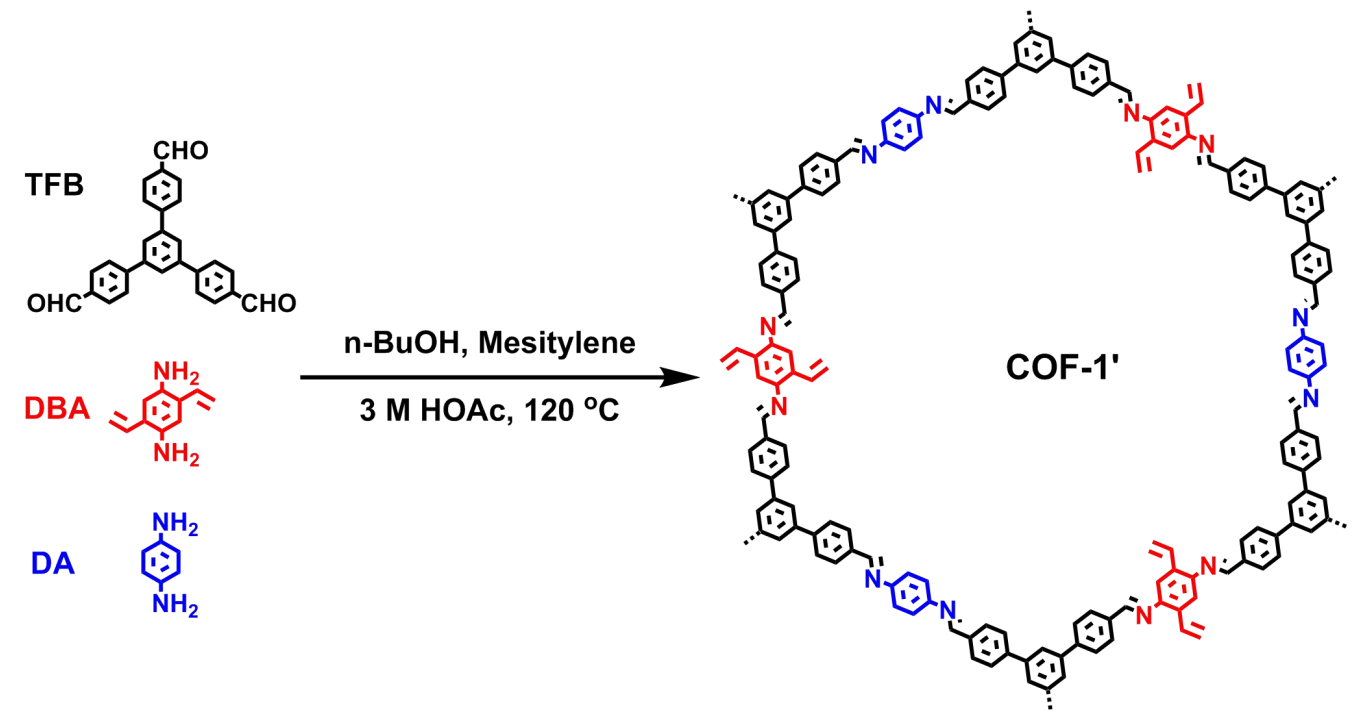

A $10 \mathrm{~mL}$ Schlenk tube was charged with TFB (25 mg, $0.064 \mathrm{mmol})$, DBA (7.7 mg, $0.048 \mathrm{mmol}), \mathbf{D A}(5.2 \mathrm{mg}, 0.048 \mathrm{mmol}), \mathrm{n}-\mathrm{BuOH}(1.0 \mathrm{~mL})$ and mesitylene $(0.5 \mathrm{~mL})$. The resulting mixture was sonicated for $10 \mathrm{~min} .3 \mathrm{M}$ acetic acid $(0.2 \mathrm{~mL})$ was then added to the solution, and the Schlenk tube was flash frozen at $77 \mathrm{~K}$ using the liquid nitrogen bath, evacuated and sealed by Teflon valve. Upon warming to room temperature, the Schlenk tube was heated at $120^{\circ} \mathrm{C}$ for 5 days. And the yellow solid was isolated by centrifugation and washed with THF $(3 \times 10 \mathrm{~mL})$ and $\mathrm{Et}_{2} \mathrm{O}(3 \times 10$ $\mathrm{mL}$ ). Further purification of COF-1' was carried out by Soxhlet extraction in THF for $24 \mathrm{~h}$. The powder was dried at $60{ }^{\circ} \mathrm{C}$ under vacuum overnight to afford $\mathrm{COF}-1$ ' as yellow powder. Yield: (30 mg, 81\%). 


\subsection{Synthesis of COF-2:}

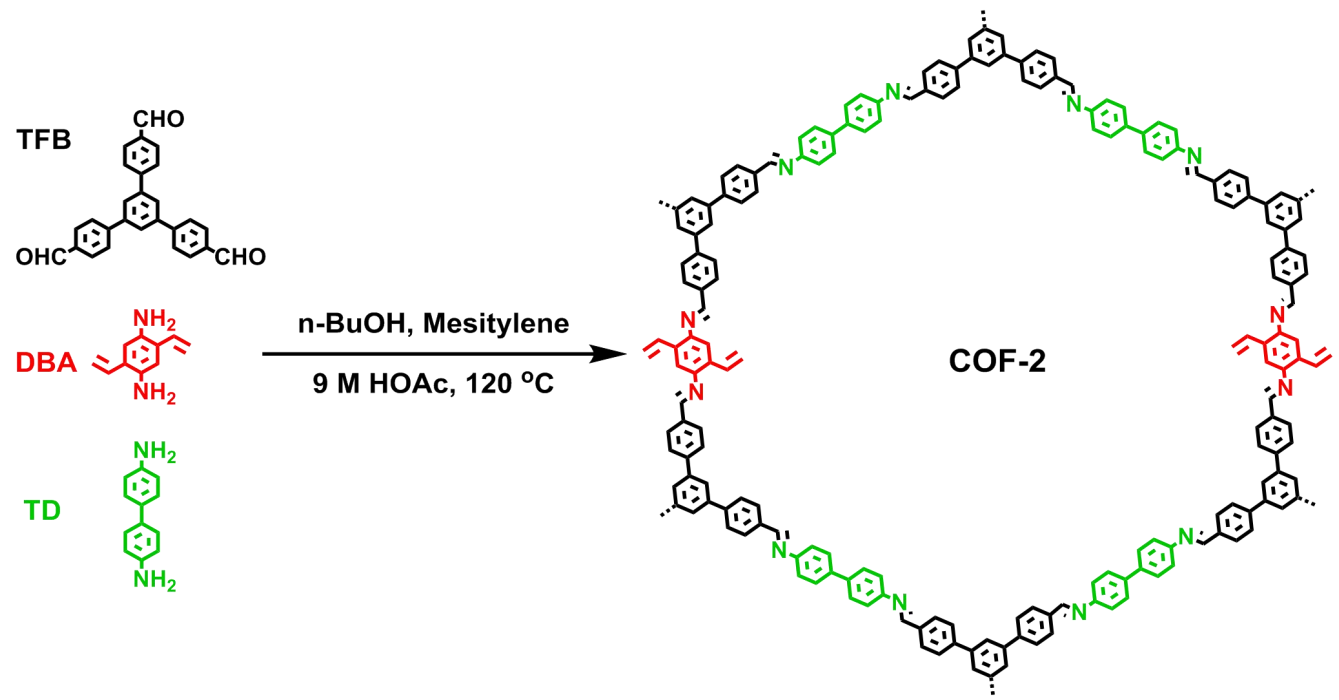

A $10 \mathrm{~mL}$ Schlenk tube was charged with TFB (25 mg, $0.064 \mathrm{mmol})$, DBA (5.1 mg, $0.032 \mathrm{mmol})$, o-tolidine (TD) $(11.8 \mathrm{mg}, 0.064 \mathrm{mmol}), \mathrm{n}-\mathrm{BuOH}(1.0 \mathrm{~mL})$ and mesitylene $(0.5 \mathrm{~mL})$. The resulting mixture was sonicated for $10 \mathrm{~min} .9 \mathrm{M}$ acetic acid $(0.1 \mathrm{~mL})$ was then added to the solution, and the Schlenk tube was flash frozen at 77 $\mathrm{K}$ using the liquid nitrogen bath, evacuated and sealed by Teflon valve. Upon warming to room temperature, the Schlenk tube was heated at $120^{\circ} \mathrm{C}$ for 5 days. And the yellow solid was isolated by centrifugation and washed with THF $(3 \times 10 \mathrm{~mL})$ and $\mathrm{Et}_{2} \mathrm{O}(3 \times 10 \mathrm{~mL})$. Further purification of COF-2 was carried out by Soxhlet extraction in THF for $24 \mathrm{~h}$. The powder was dried at $60{ }^{\circ} \mathrm{C}$ under vacuum overnight to afford COF-2 as yellow powder. Yield: (34 mg, 81\%). 


\subsection{Synthesis of CD-COFs:}

6-deoxy-6-mercapto- $\beta$-cyclodextrin was synthesized according to the published procedure. $^{2}$

To the mixture of COF $(100 \mathrm{mg})$, 6-deoxy-6-mercapto- $\beta$-cyclodextrin $(500 \mathrm{mg})$, and azobisisobutyronitrile (AIBN, $10 \mathrm{mg}$ ) in a $25 \mathrm{~mL}$ Schlenk tube, trifluorotoluene $(4.0 \mathrm{~mL})$ was introduced under $\mathrm{N}_{2}$ atmosphere. After stirring at $80{ }^{\circ} \mathrm{C}$ for 48 hours, the title product was isolated by filtration, washed with DMF, $\mathrm{H}_{2} \mathrm{O}$, THF and acetone, dried under vacuum at $60{ }^{\circ} \mathrm{C}$.

\subsection{Preparation of membranes:}

Bare polyethersulfone (PES) membrane was prepared by the phase-inversion method. $600 \mathrm{mg}$ PES was dissolved in $0.18 \mathrm{~mL}$ anhydrous DMF. Then the resulting solution was cast onto a flat glass surface with the help of a doctor blade knife, the solvent was evaporated at $100{ }^{\circ} \mathrm{C}$ for 30 minutes. The glass plate was then put into deionized water and the free-standing bare PES membrane was peeled off from the glass surface.

CD-COF mixed-matrix membranes (MMMs) were also prepared by the phase-inversion method. $580 \mathrm{mg}$ PES was dissolved in anhydrous $0.18 \mathrm{~mL}$ DMF. The resulting solution was mixed with $20 \mathrm{mg}$ CD-COFs and stirred for 2-3 days in order to obtain a homogeneous suspension. The suspension was poured on a flat glass surface with the help of a doctor blade knife, the solvent was evaporated at $100{ }^{\circ} \mathrm{C}$ for 30 minutes. The glass plate was then put into deionized water and the free-standing MMM was peeled off from the glass surface. 


\section{The stability tests.}

The samples were immersed in different solvents for 7 days and then washed with anhydrous THF for three times. At last, the samples were activated at $60{ }^{\circ} \mathrm{C}$ under high vacuum. And for the stability test in acid or base, the samples were immersed in different aqueous solutions for 3 days and then washed with water and anhydrous EtOH for three times. At last, the samples were activated at $60^{\circ} \mathrm{C}$ under high vacuum.

Figure S1. The stability test of COFs after treated by different solvents.

a)

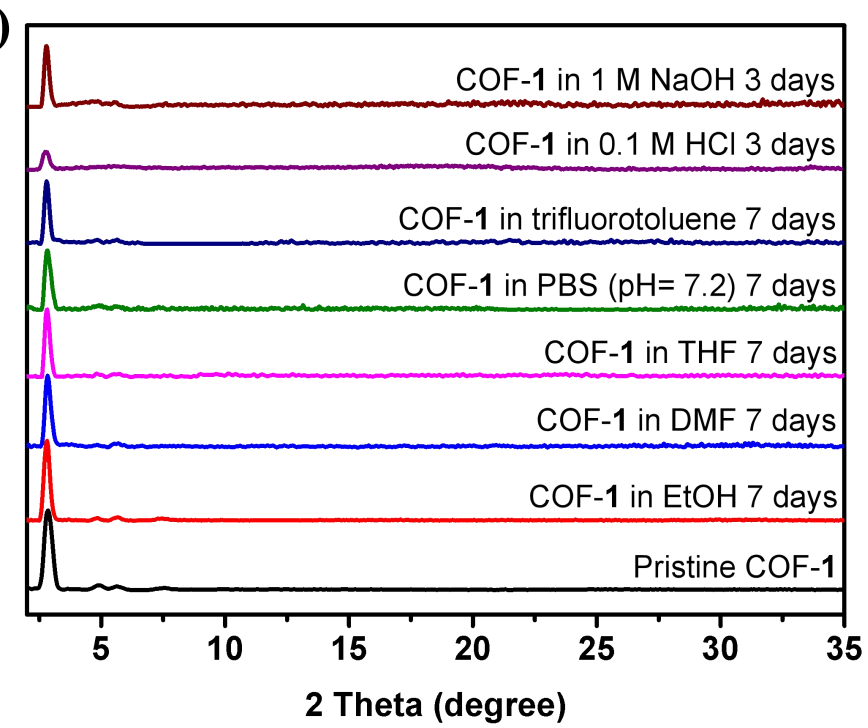

b)

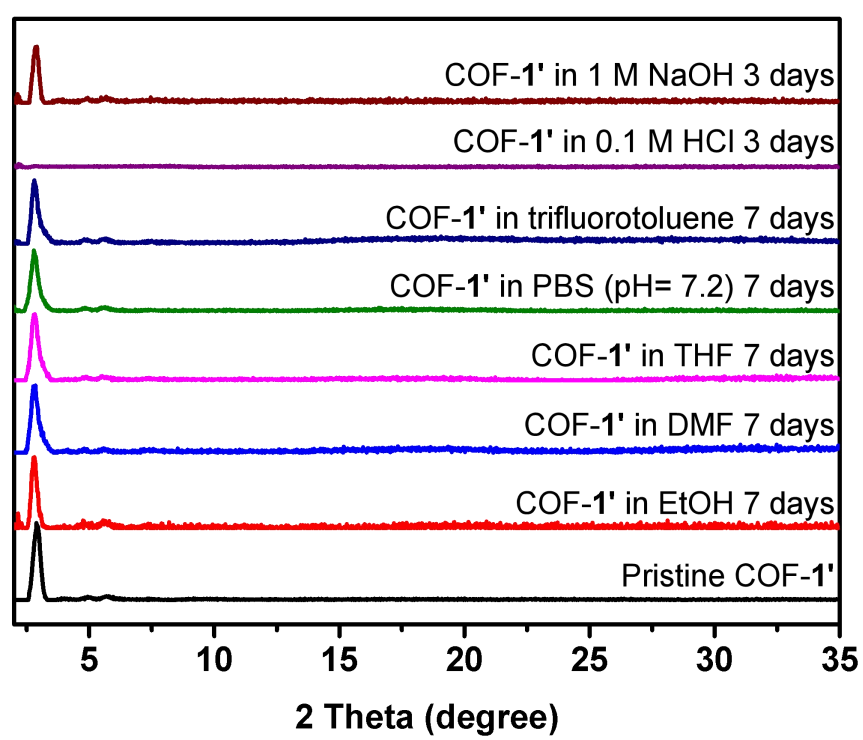




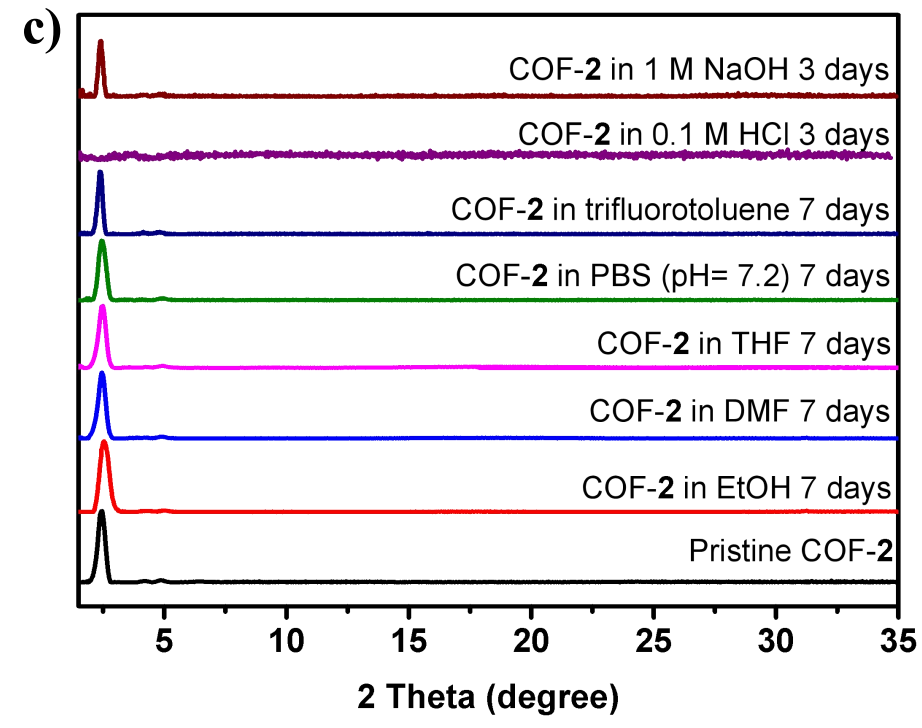




\section{Figure S2. FT-IR spectra.}
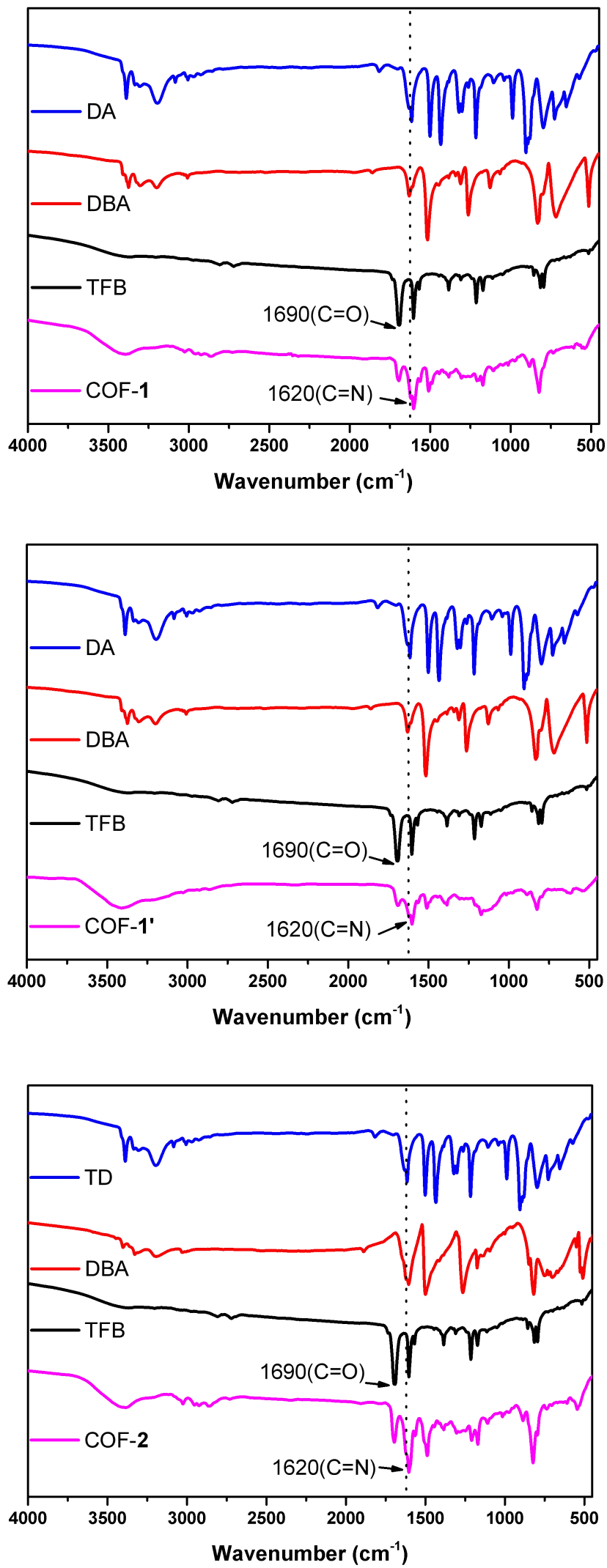
5. Figure S3. Solid-state ${ }^{13} \mathrm{C}$ NMR spectras.
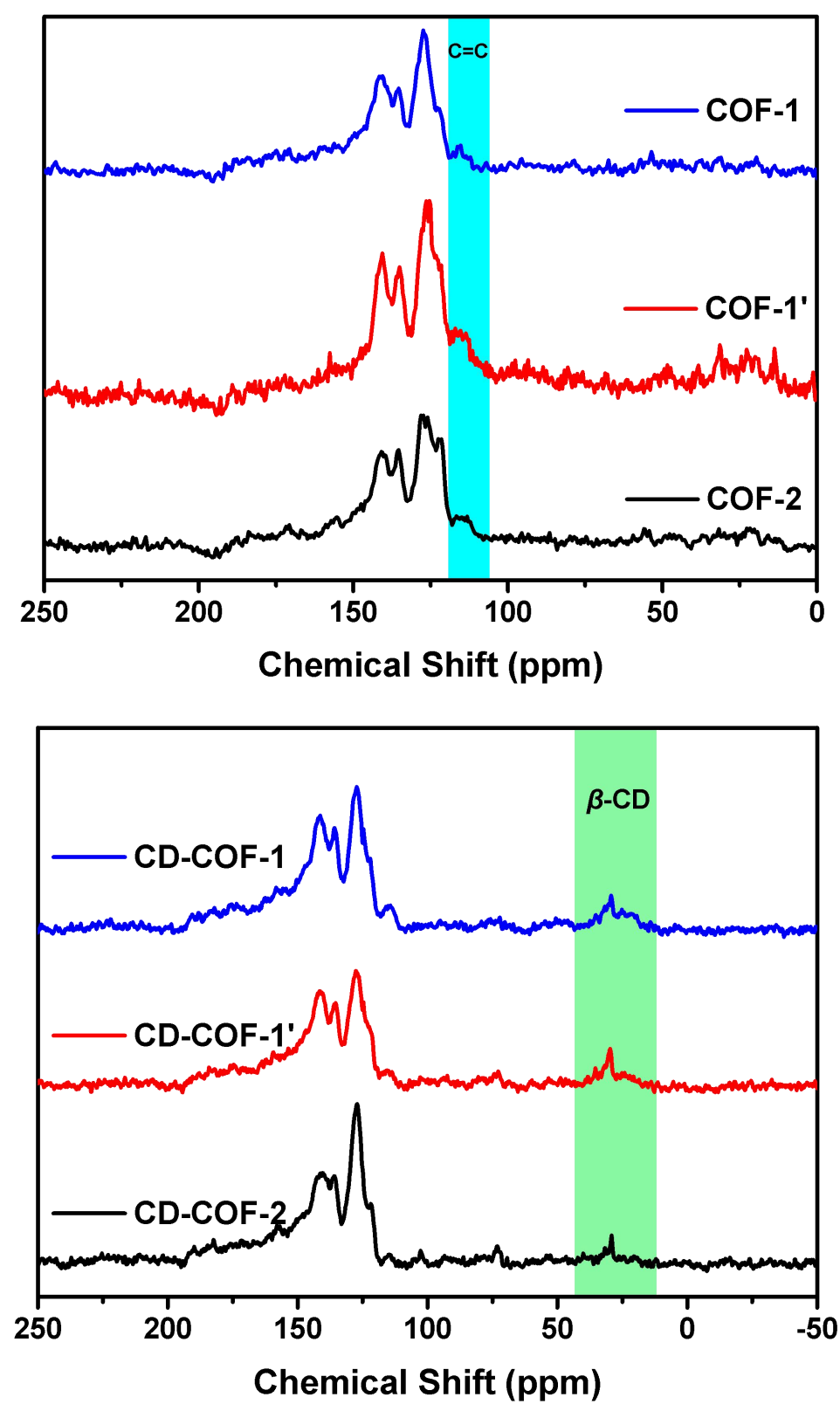


\section{SEM images of COFs.}

Figure S4. SEM of COF-1 (a), CD-COF-1 (b), COF-1' (c), CD-COF-1' (d), COF-2 (e) and CD-COF-2 (f).
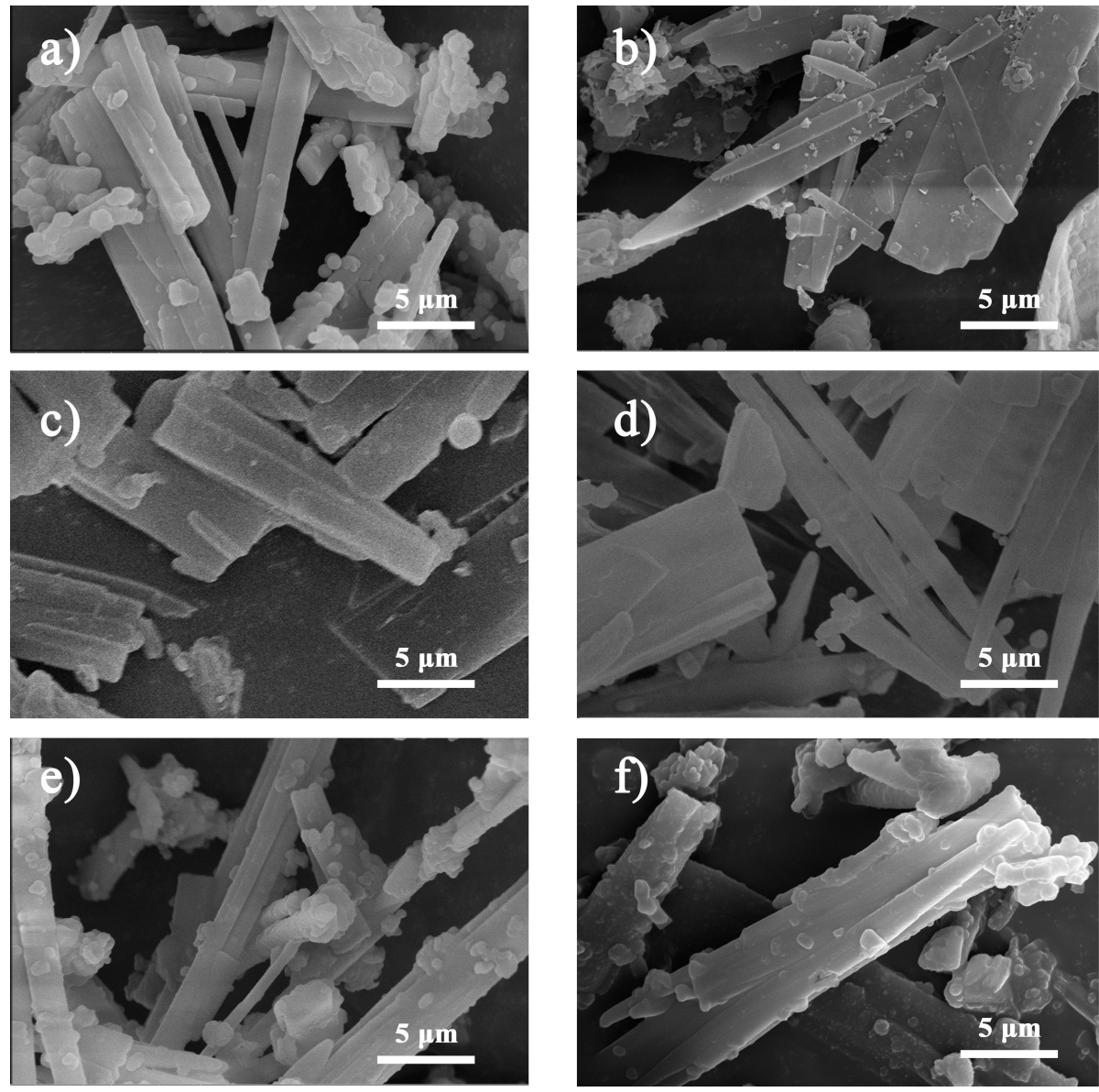
7. Figure S5. TEM images of COF-1 (a), COF-2 (b) and COF-1' (c).
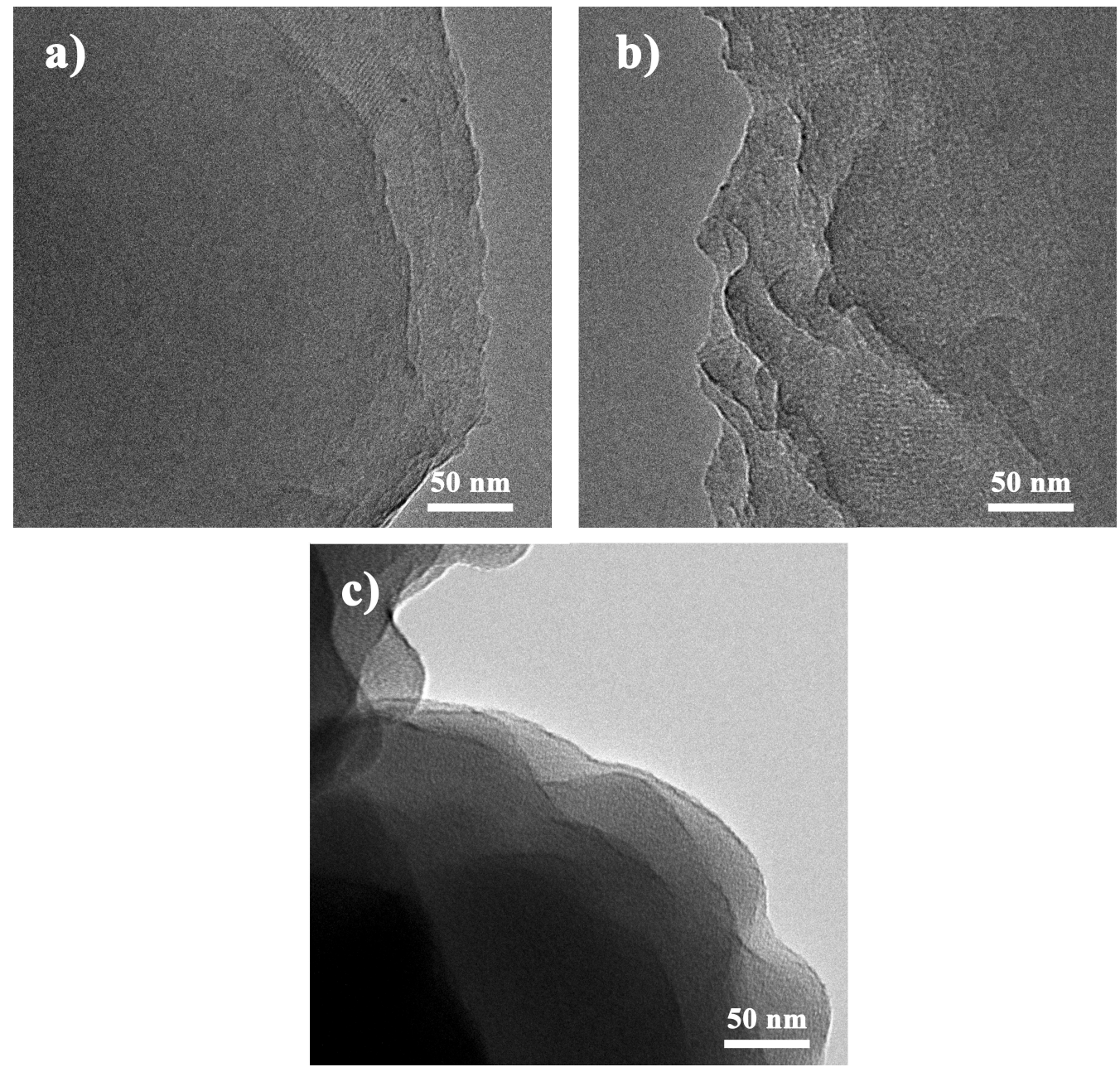


\section{Structural modeling and PXRD analysis of the COFs.}

Molecular modeling of COFs was generated with the Materials Studio (ver. 7.0) suite of programs. Pawley refinement was carried out using Reflex, a software package for crystal determination from PXRD pattern. Unit cell dimension was set to the theoretical parameters. The Pawley refinement was performed to optimize the lattice parameters iteratively until the $\mathrm{R}_{w p}$ value converges and the overlay of the observed with refined profiles shows good agreement. The lattice models (e.g., cell parameters, atomic positions, and total energies) were then fully optimized using MS Forcite molecular dynamics module (universal force fields, Ewald summations) method.

For COF-1 and COF-2, considering the geometry of the precursors and the connection patterns, only a few topologies are reasonable.

Figure S6. Space-filling models of COF-1 with AB stacking mode (a) and ABC stacking mode (b). Carbon, gray; Nitrogen, blue; Hydrogen atoms are omitted.

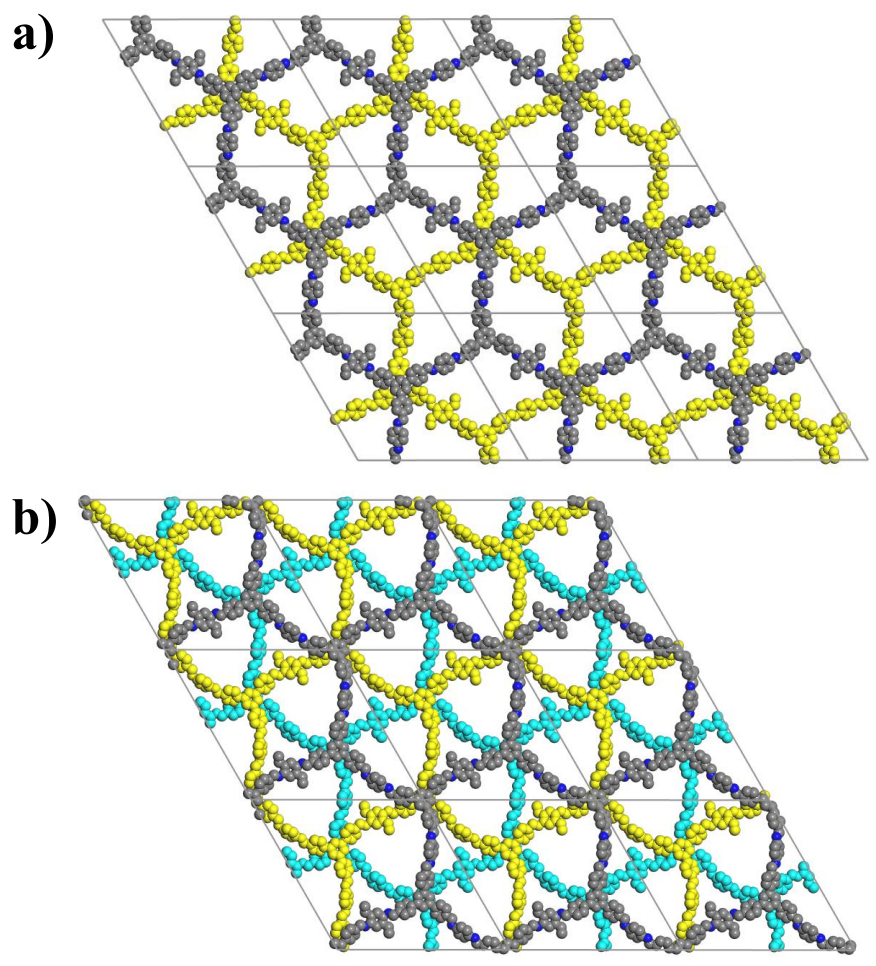


Figure S7. The calculated PXRD profiles of COF-1: AA stacking mode (bule), AB stacking mode (pink), ABC stacking mode (green). The experimental pattern was also presented (black).

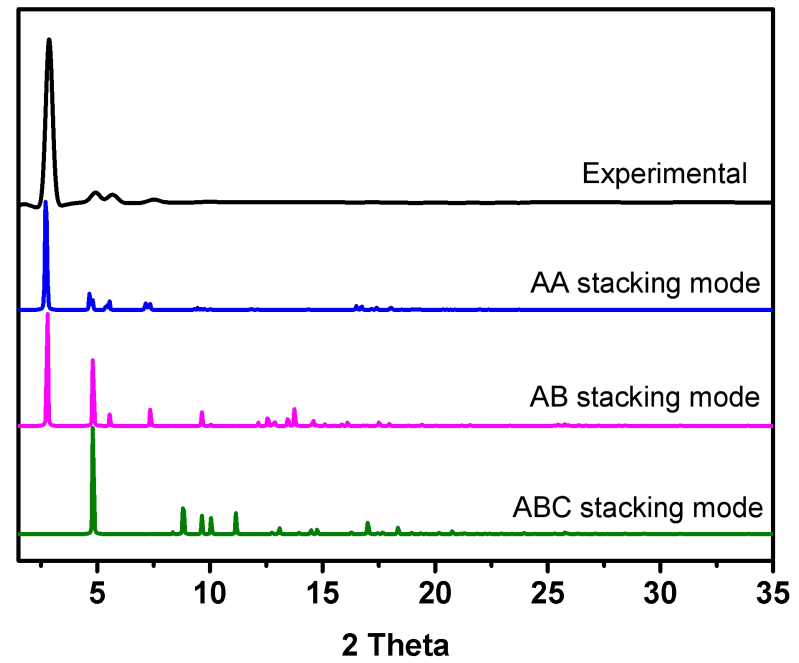

Figure S8. Space-filling models of COF-2 with AA stacking mode (a) and ABC stacking mode (b). Carbon, gray; Nitrogen, blue; Hydrogen atoms are omitted.

a)

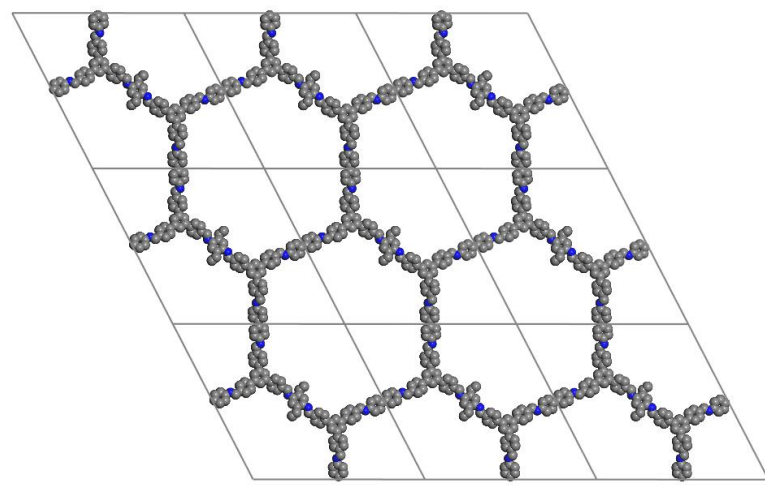

b)

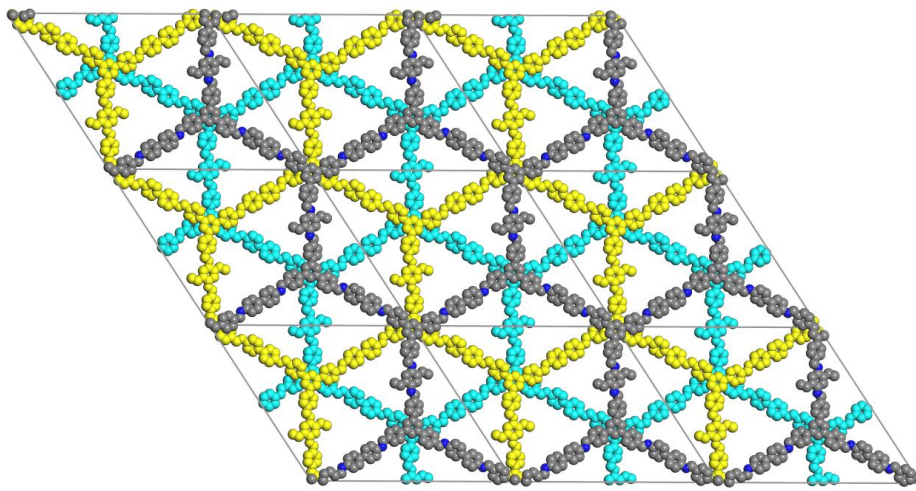


Figure S9. The calculated PXRD profiles of COF-2: AA stacking mode (bule), AB stacking mode (pink), ABC stacking mode (green). The experimental pattern was also presented (black).

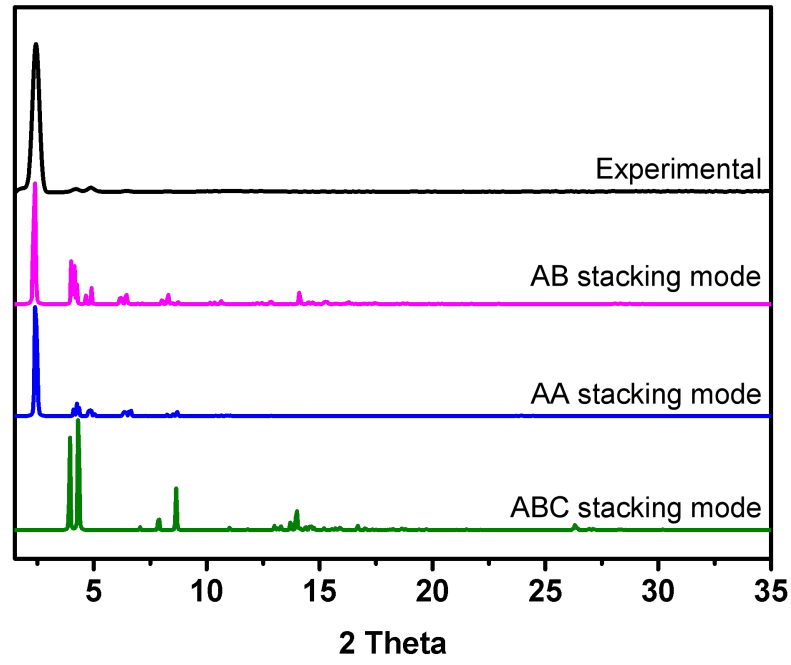




\section{Characterization of CD-COFs.}

Figure S10. BET plots of the COFs.
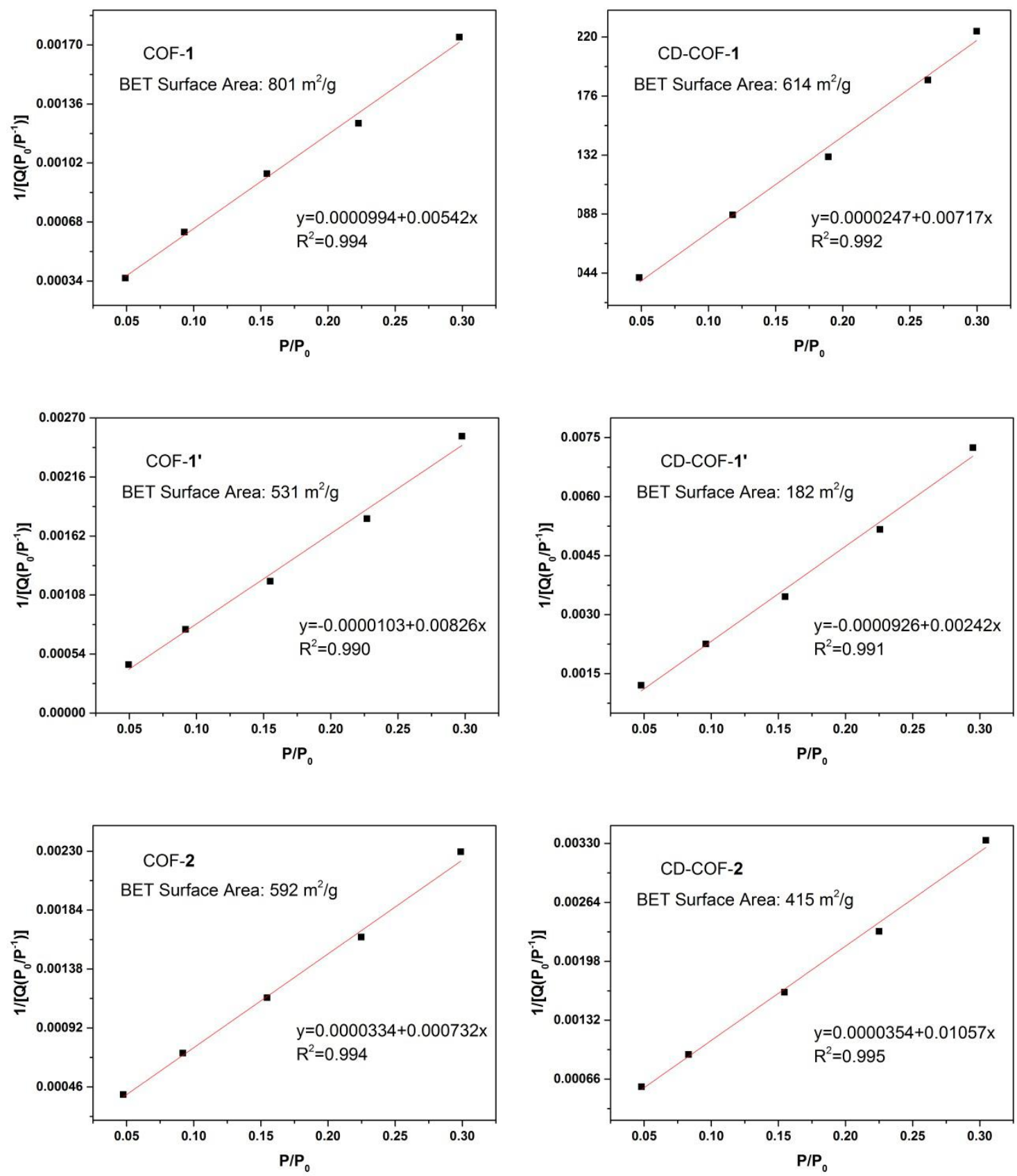
Figure S11. FT-IR spectra of CD-COF-1, CD-COF-1' and CD-COF-2.
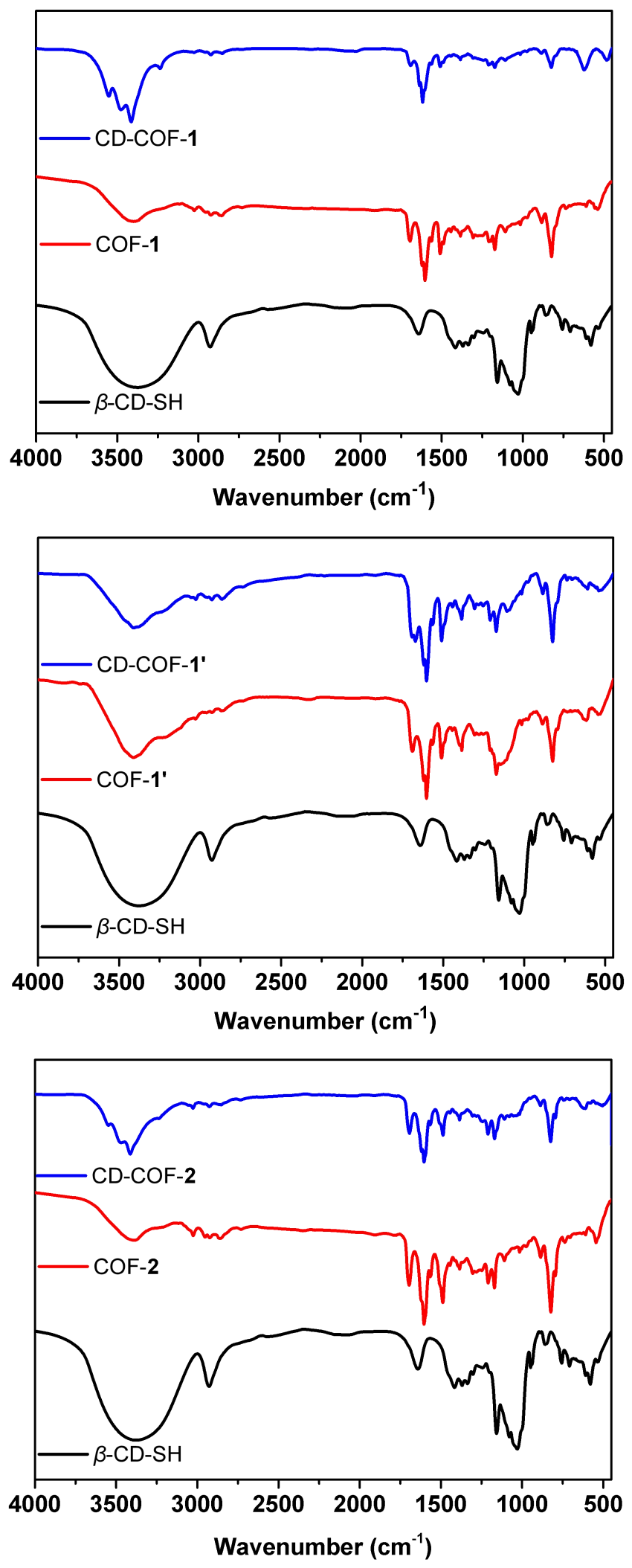
Figure S12. ${ }^{1} \mathrm{H}$ NMR spectra of the digested COFs.

The COFs were dispersed in DCOOD $\left(95 \%\right.$ solution in $\left.\mathrm{D}_{2} \mathrm{O}\right)$ and heat to $70{ }^{\circ} \mathrm{C}$ overnight. The digestion is finished when the solid disappear. Then the percent loadings of $\beta$-CD into COFs were evaluated by $\mathrm{H}^{1} \mathrm{NMR}$ spectroscopy by integrating the CD's resonance peak and TFB's resonance peak intensities after the material digested. The temperature for the proton NMR experiment is $297 \mathrm{~K}$
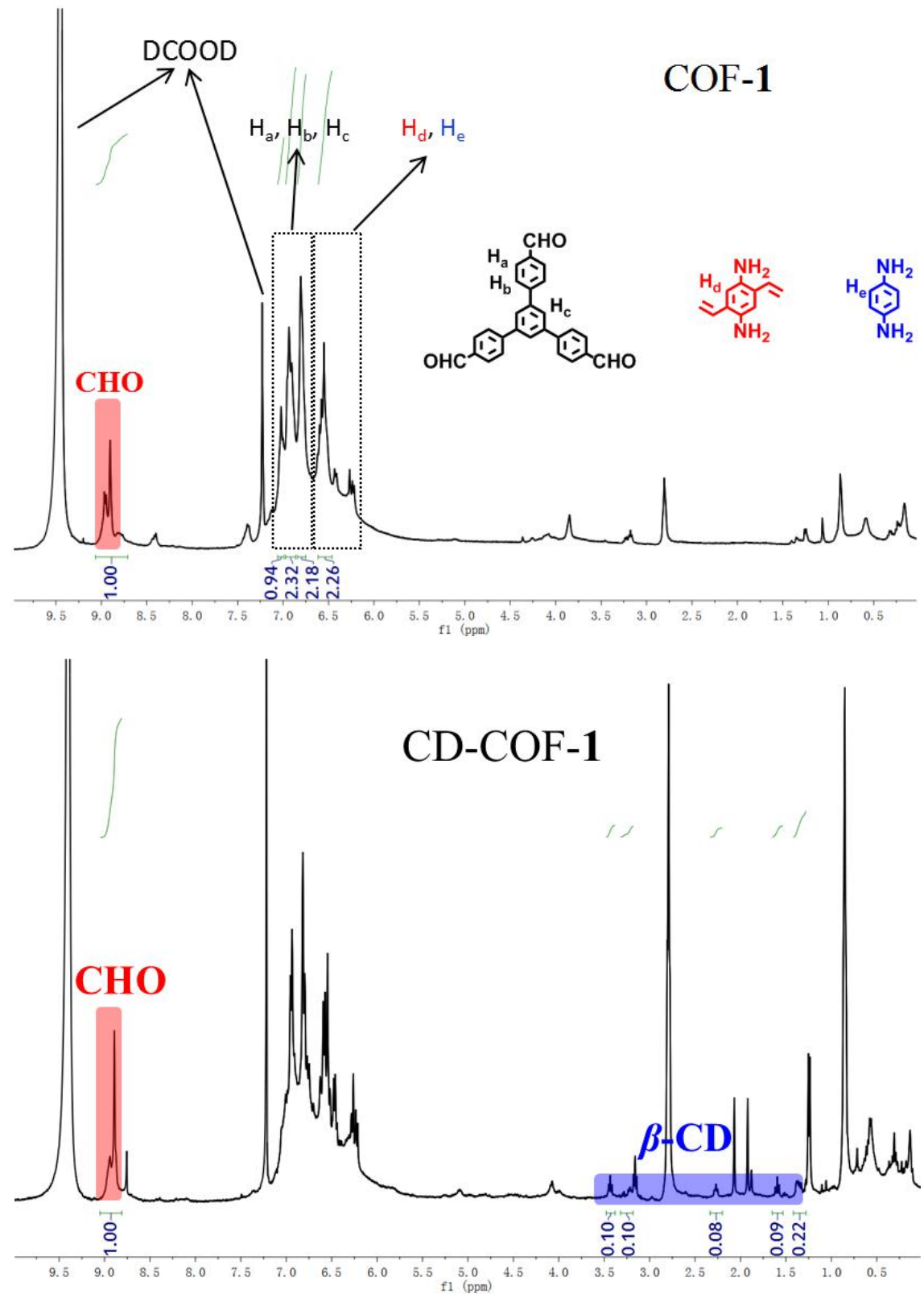

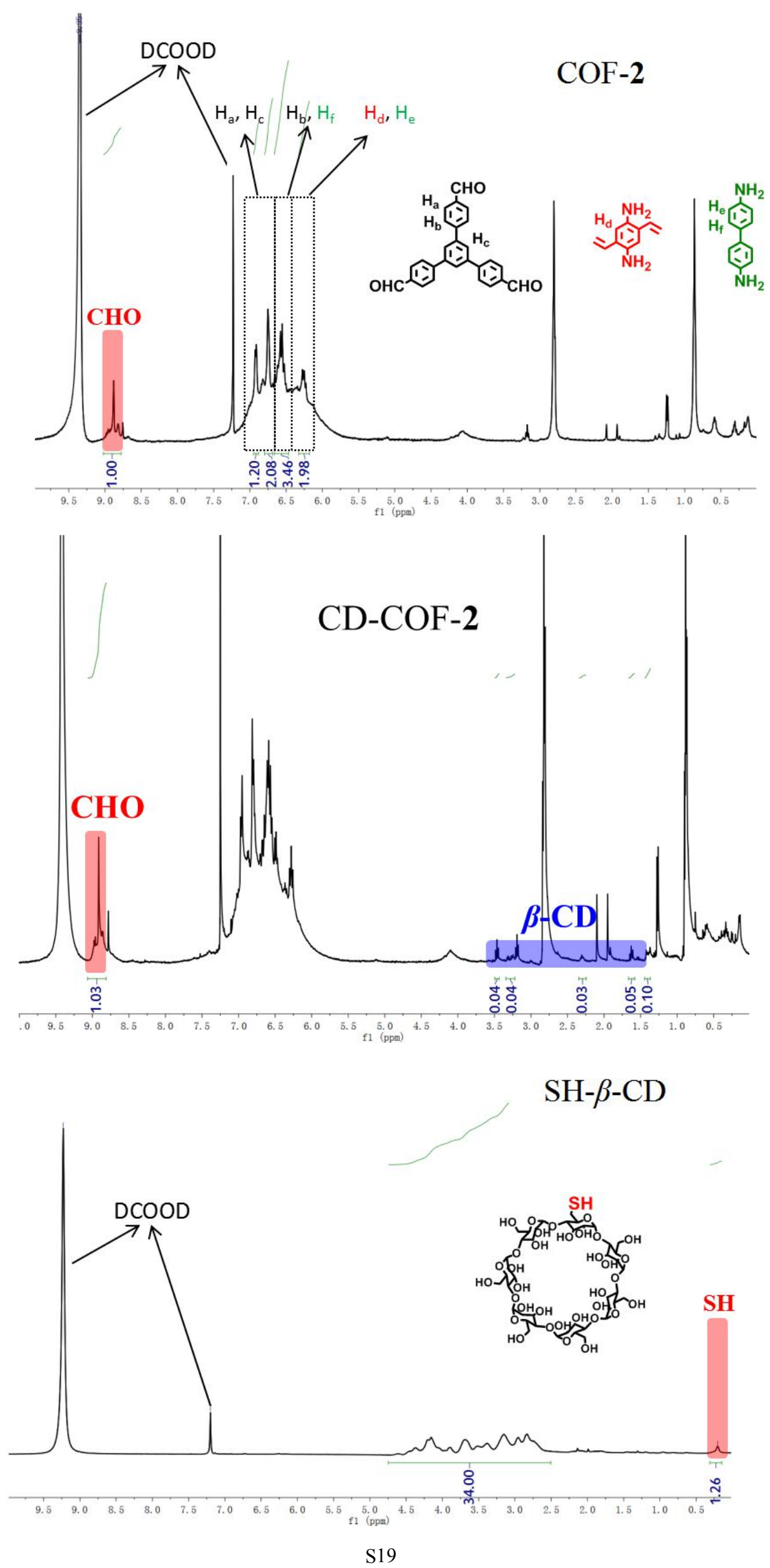


\section{Optic photos and SEM of COF MMMs.}

Figure S13. Optic photos of CD-COF-1' MMM and CD-COF-2 MMM.
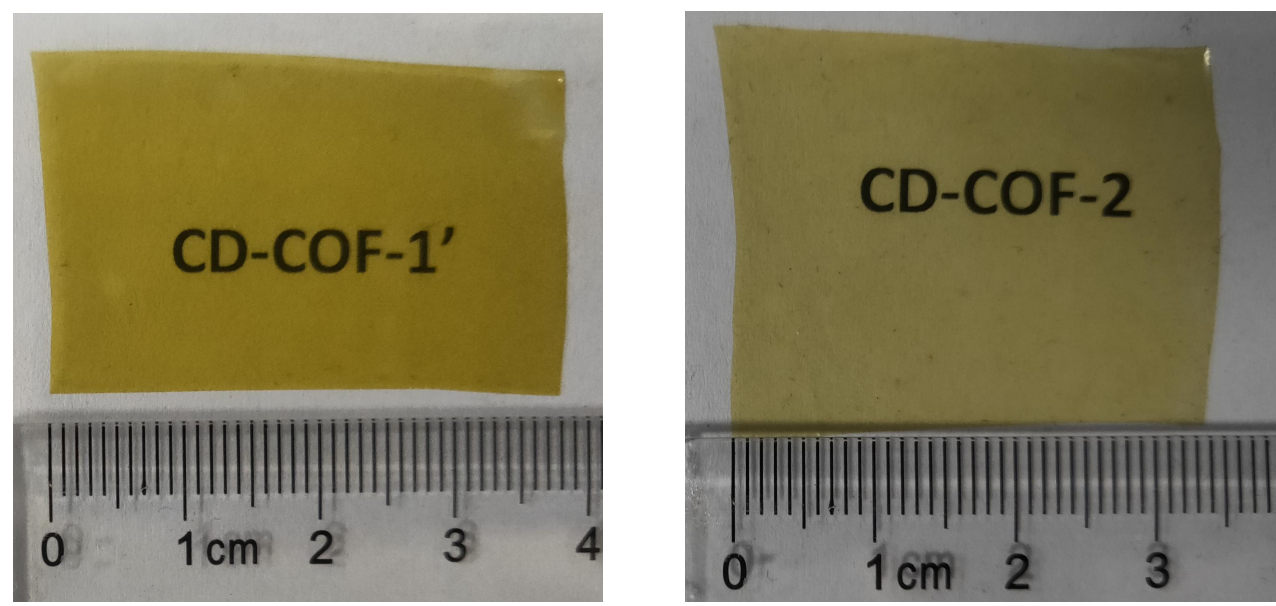

Figure S14. SEM of surface of CD-COF-1' MMM (a), CD-COF-2 MMM (b) and cross-section of CD-COF-1' MMM (c) and CD-COF-2 MMM (d).

a)

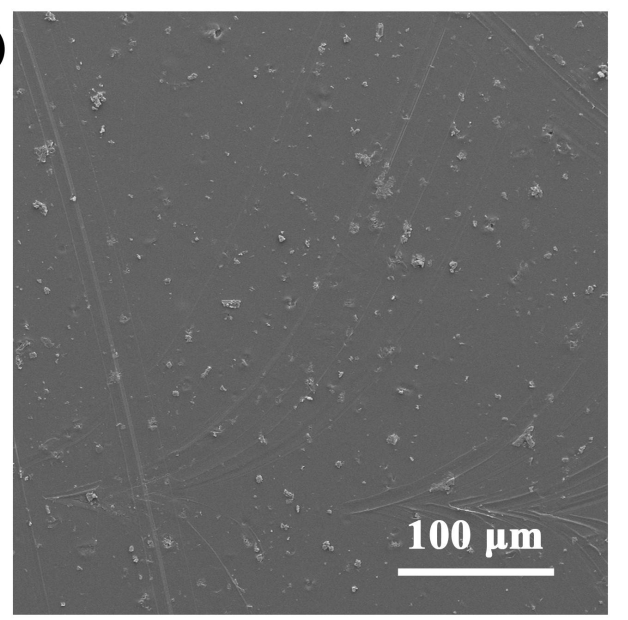

c)

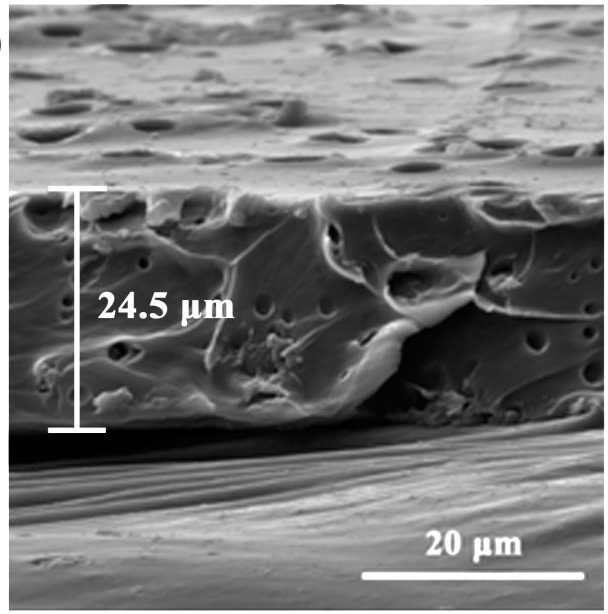

b) d)

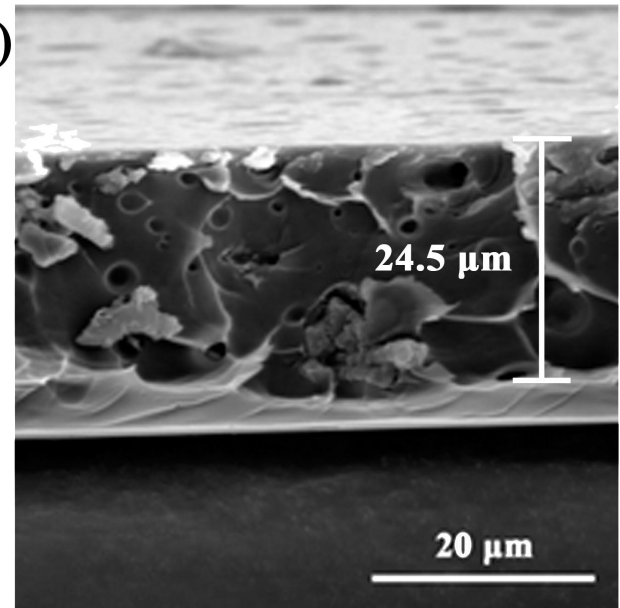




\section{Ionic current measurement.}

Ion currents were measured by an Axon Axopatch 200B Capacitor Feedback Patch Clamp Amplifier (Molecular Devices, Union City, CA, US). Data were acquired by using a DigiData 1550A converter and a PC running PClamp 10.6 (Axon Instruments, Forest City, CA, USA). $\mathrm{Ag} / \mathrm{AgCl}$ electrodes were used to apply a transmembrane potential across the film. The COF MMM was placed between the two chambers of the conductance cell, and the both half of the cell were filled with text buffered saline (20 mM PBS, $1 \mathrm{M} \mathrm{KCl}, \mathrm{pH}$ 7.2). The transmembrane potential used in this work was a scanning voltage varied from -1 to $+1 \mathrm{~V}$ with a $60 \mathrm{~s}$ period. Each test was repeated 3 times to obtain the average current value at different voltage. The responsive chiral amino acids transport properties of MMMs were evaluated by measuring the ion current across the membrane in electrolyte at $-1 \mathrm{~V}$.

Figure S15. Schematic illustration of ion current measurement.

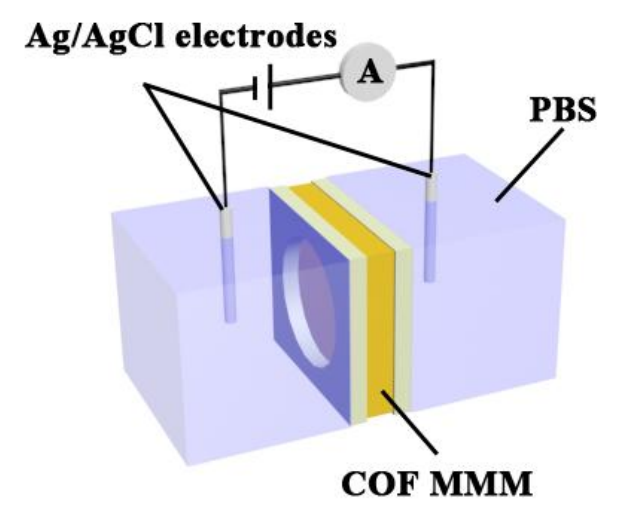

Figure S16. $I-V$ curves for the bare PES membrane, CD-COF-1 MMM and CD-COF-2 MMM in text buffer (20 mM PBS, $1 \mathrm{M} \mathrm{KCl,} \mathrm{pH} \mathrm{7.2).}$

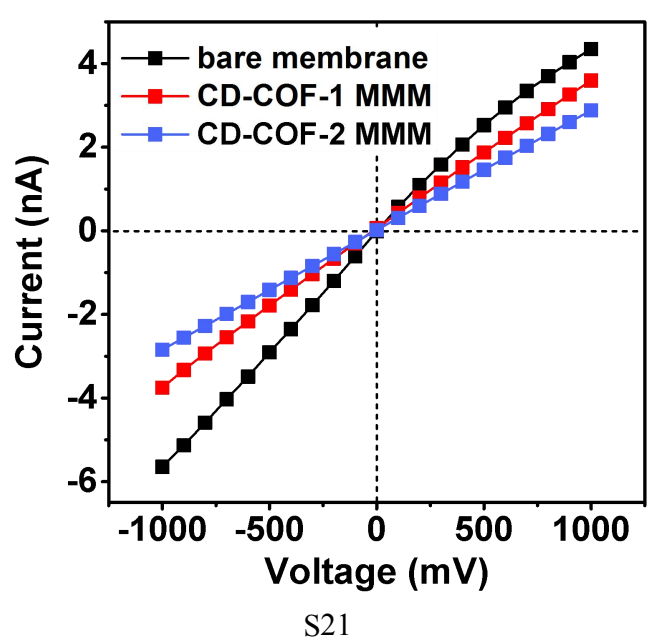




\section{Contact angle measurements.}

Contact angles were measured using a DSA 30 machine (Kruss, Germany) contact-angle system at ambient temperature and saturated humidity. In each measurement, an about $1 \mu \mathrm{L}$ droplet of water was dispensed onto the substrates under investigation. The average contact angel value was obtained at three different positions for one membrane. The bare PES membrane and CD-COF-1 MMM were treated with deionized water overnight. Before the contact angle measurements, the samples were blown dry with $\mathrm{N}_{2}$. For bare PES membrane, the mean water contact angle was $66.3 \pm 1.8^{\circ}$. And for the CD-COF-1 MMM, because of the hydrophobic property of COF, the mean water contact angle became $75.2 \pm 3.4^{\circ}$. The CD-COF-1 MMM had different wettability: $74.7 \pm 4.3^{\circ}$ in $D$-His and $87.6 \pm 1.2^{\circ}$ in $L$-His. All these changes of wettability in membranes reveal the change of chemical composition.

Figure S17. Photographs of water droplet shape on bare PES membrane, CD-COF-1 MMM and CD-COF-1 MMMs after immersing into the $D$ - or $L$-His solutions (20 mM PBS, pH 7.2) overnight.

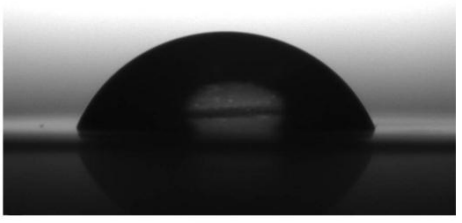

bare PES membrane $66.3 \pm 1.8^{\circ}$

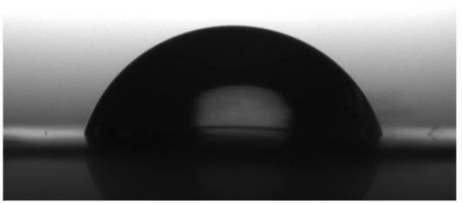

CD-COF-1 MMM + D-His $74.7 \pm 4.3^{\circ}$

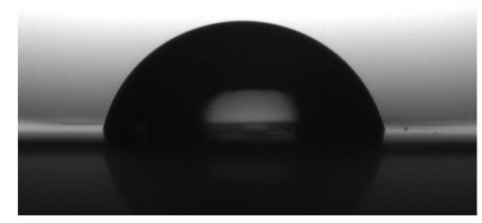

CD-COF-1 MMM $75.2 \pm 3.4^{\circ}$

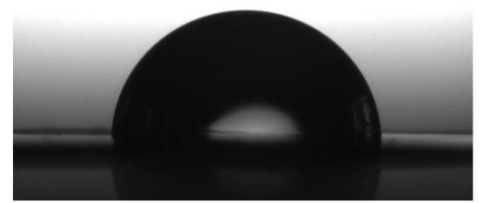

CD-COF-1 MMM + L-His $87.6 \pm 1.2^{\circ}$ 


\section{Surface zeta potential measurements.}

Surface zeta potentials of membranes were measured using a Zetasizer Nano ZS ZEN3600 machine (Malvern Instruments, UK). The CD-COF-1 MMM was treated with $20 \mathrm{mM}$ PBS (pH 7.2), $5 \mathrm{mM} L$ - or $D$-His solution (20 mM PBS, pH 7.2) and $L$ or $D$-Trp aqueous solution (20 mM PBS, pH 7.2) overnight. Before the surface zeta potential measurements, the samples were washed with deionized water and blown dry with $\mathrm{N}_{2}$. The changes of surface zeta potential of CD-COF-1 MMM reveal the change of chemical composition.

Table S1. Surface zeta potential of membranes.

\begin{tabular}{ccc}
\hline Sample name & $\begin{array}{c}\text { Surface zeta potential } \\
/ \mathrm{mV}\end{array}$ & $\begin{array}{c}\text { Surface zeta potential } \\
\text { uncertainty } / \mathrm{mV}\end{array}$ \\
\hline CD-COF-1 MMM & -11.8 & 1.99 \\
CD-COF-1 MMM + D-His & -14.2 & 3.20 \\
CD-COF-1 MMM + L-His & -16.7 & 3.40 \\
CD-COF-1 MMM + D-Trp & -18.6 & 3.09 \\
CD-COF-1 MMM + L-Trp & -18.2 & 3.04 \\
\hline
\end{tabular}


Zeta potentials of CD-COF-1 particles were measured using a Zetasizer Nano ZS90/ZS machine (Malvern Instruments, UK). The CD-COF-1 particles were soaked in $20 \mathrm{mM}$ PBS (pH 7.2), $5 \mathrm{mM} L$ - or $D$-His solution (20 mM PBS, pH 7.2) overnight. Before the zeta potential measurements, the samples were washed with deionized water three times and blown dry with $\mathrm{N}_{2}$. The suspension of COF particles in $20 \mathrm{mM}$ PBS (1 M KCl, pH 7.2) was tested and then the zeta potentials of CD-COF-1 particles were obtained. Each dataset is tested five times to obtain the average zeta potential value. The changes of zeta potential of CD-COF-1 particles reveal the change of chemical composition and the surface negative charge increase.

Table S2. Zeta potential of CD-COF-1 particles.

\begin{tabular}{ccc}
\hline Sample name & Zeta potential / $\mathrm{mV}$ & $\begin{array}{c}\text { Zeta potential } \\
\text { uncertainty } / \mathrm{mV}\end{array}$ \\
\hline CD-COF-1 & -2.92 & 0.08 \\
CD-COF-1 + D-His & -2.68 & 0.14 \\
CD-COF-1 + L-His & -4.87 & 0.32 \\
\hline
\end{tabular}


14. Figure S18. Effect of increasing concentrations of His on the rectification ratios of CD-COF-1 MMM.

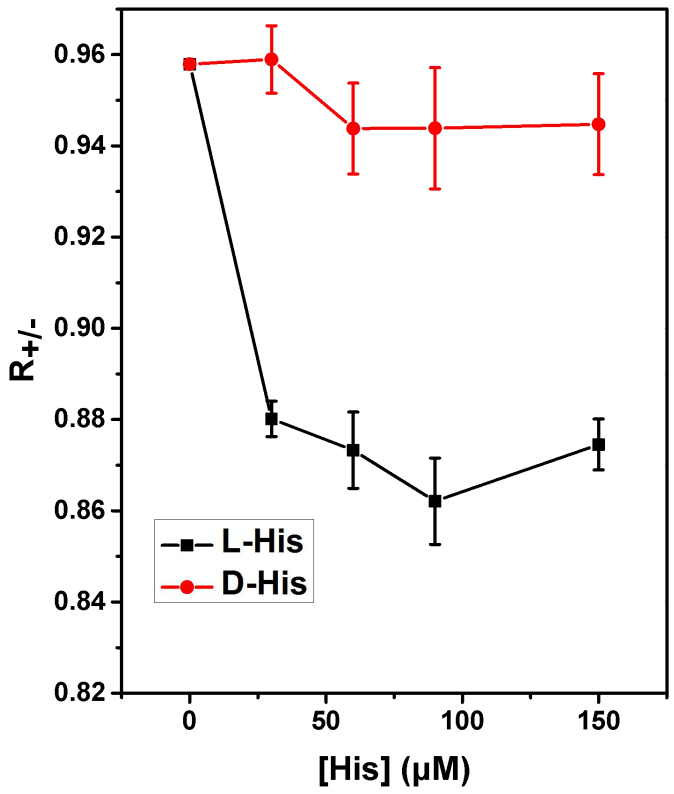




\section{I-V characteristics of COF MMMs.}

Figure S19. $I-V$ characteristics of a CD-COF-1 MMM in $20 \mathrm{mM}$ PBS prior to and after the addition of $1.5 \mathrm{mM} L / D$-His at $\mathrm{pH} 8.0, \mathrm{pH} 7.6$ and $\mathrm{pH} 5.7$.
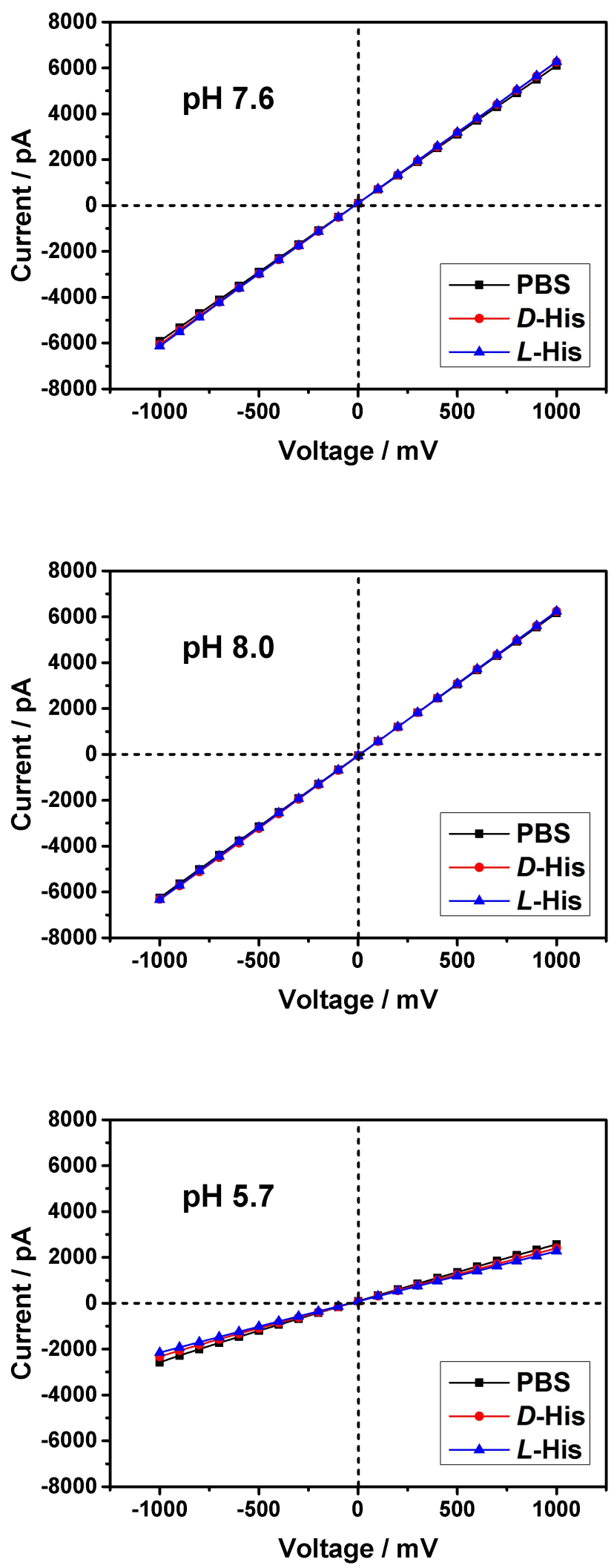
Figure S20. $I-V$ characteristics of the CD-COF-1 MMM in $20 \mathrm{mM}$ PBS (pH 7.2) with adding different concentrations of (a) $D$-His and (b) $L$-His $(0-1500 \mu \mathrm{M})$.
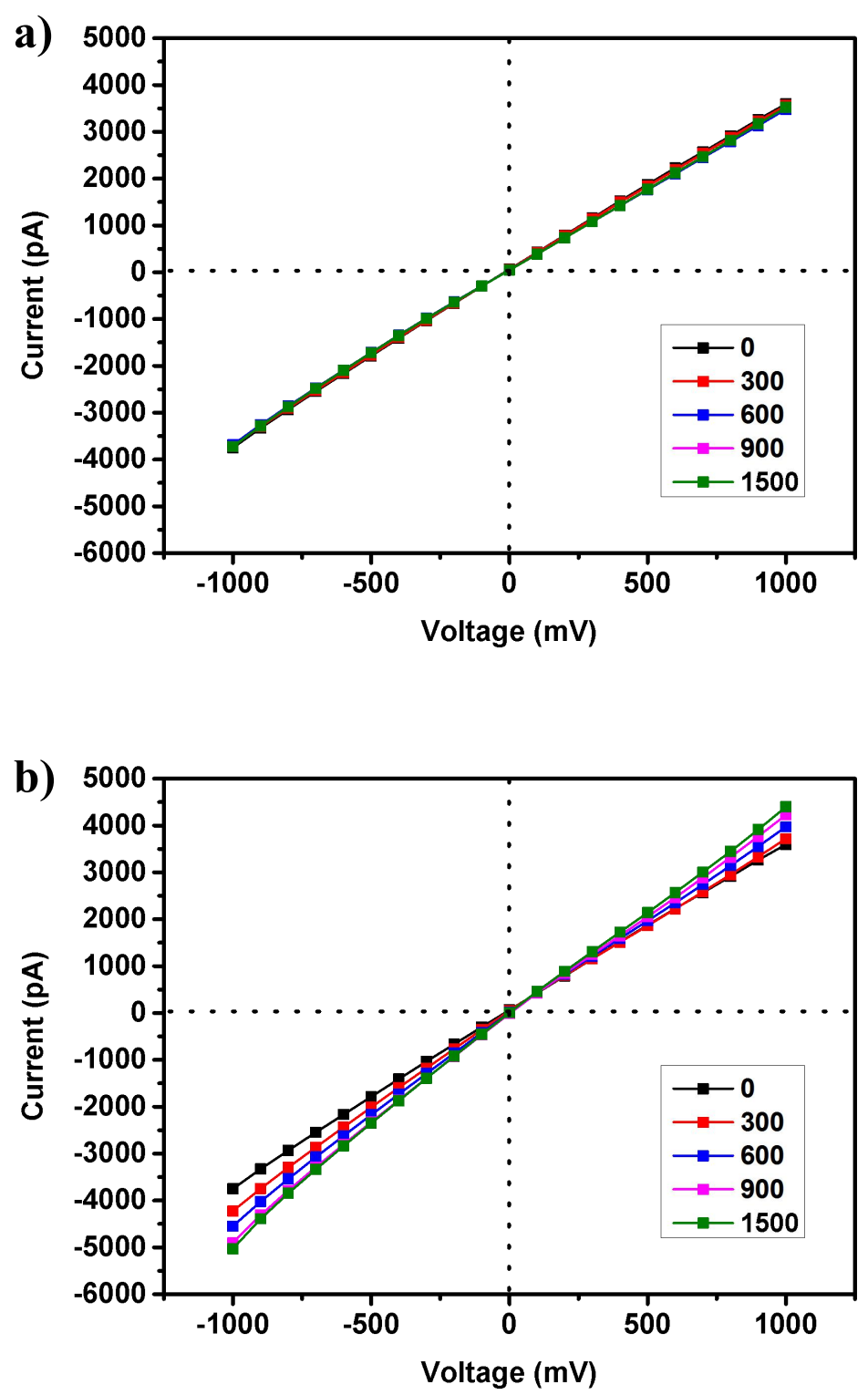
Figure S21. $I-V$ characteristics of the CD-COF-2 MMM in $20 \mathrm{mM}$ PBS (pH 7.2) with adding different concentrations of (a) $D$-His and (b) $L$-His $(0-1500 \mu \mathrm{M})$.
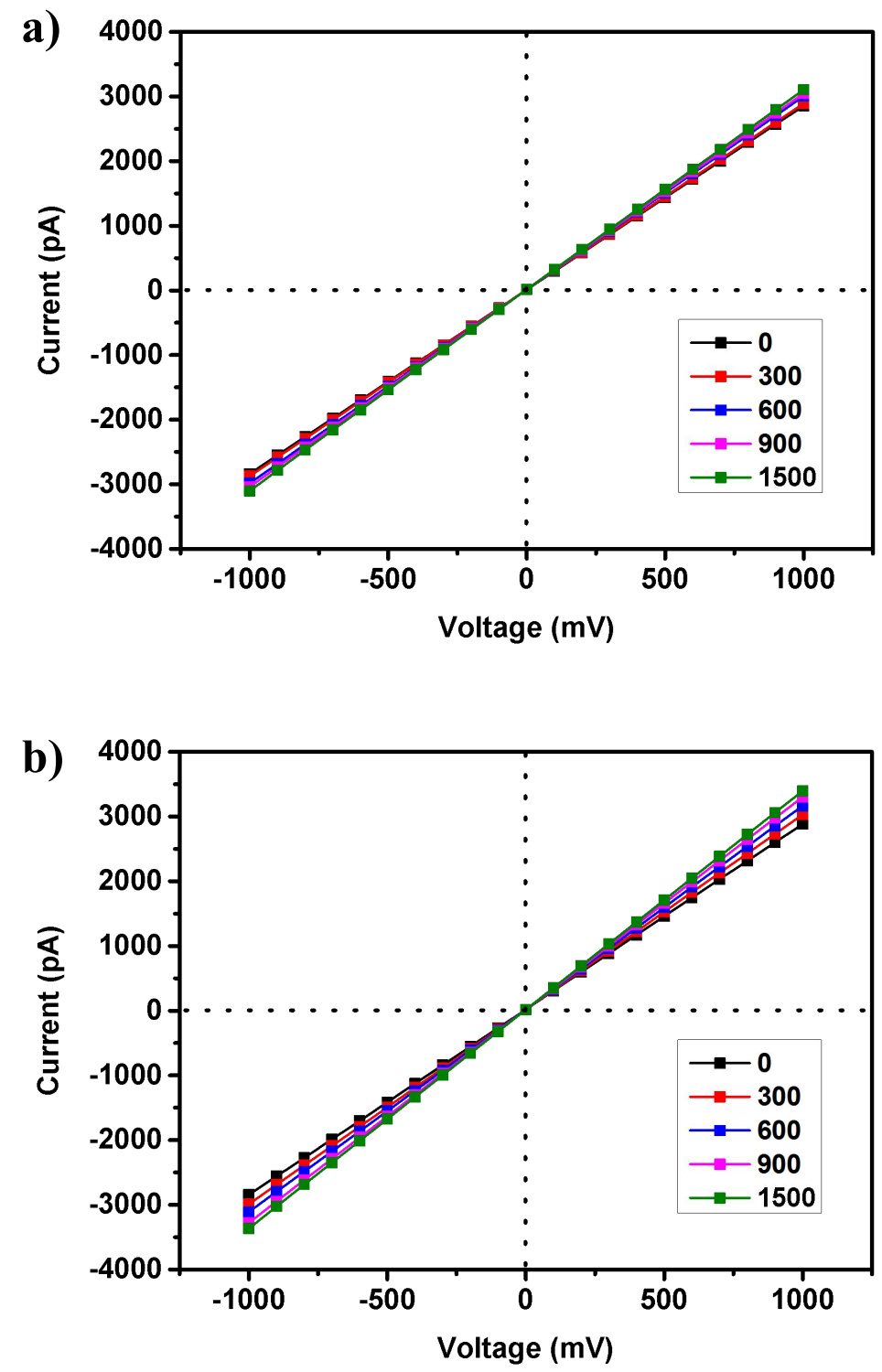
16. Characterization of CD-COF-1'.

Figure S22. The PXRD patterns of CD-COF-1'.

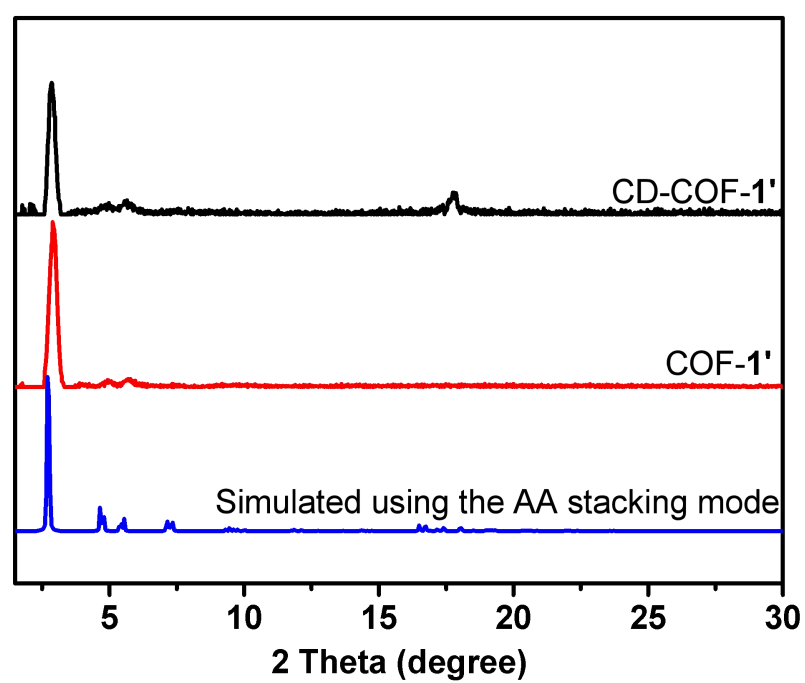

Figure S23. Top view of the structure of CD-COF-1'.

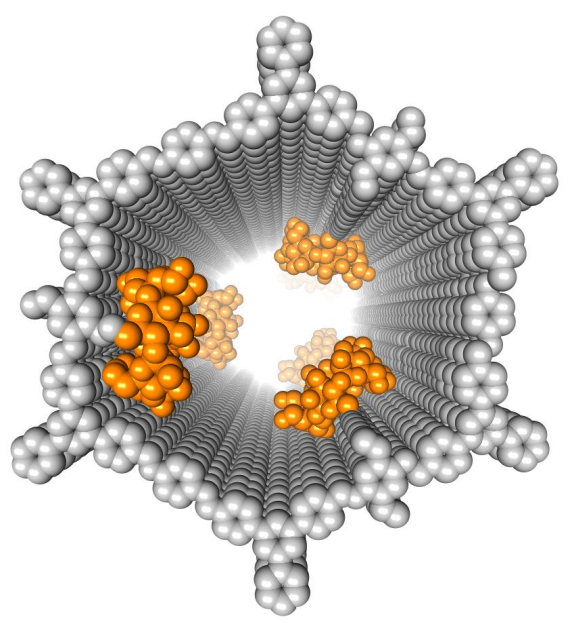


Figure S24. TGA curves of COF-1' and CD-COF-1'.
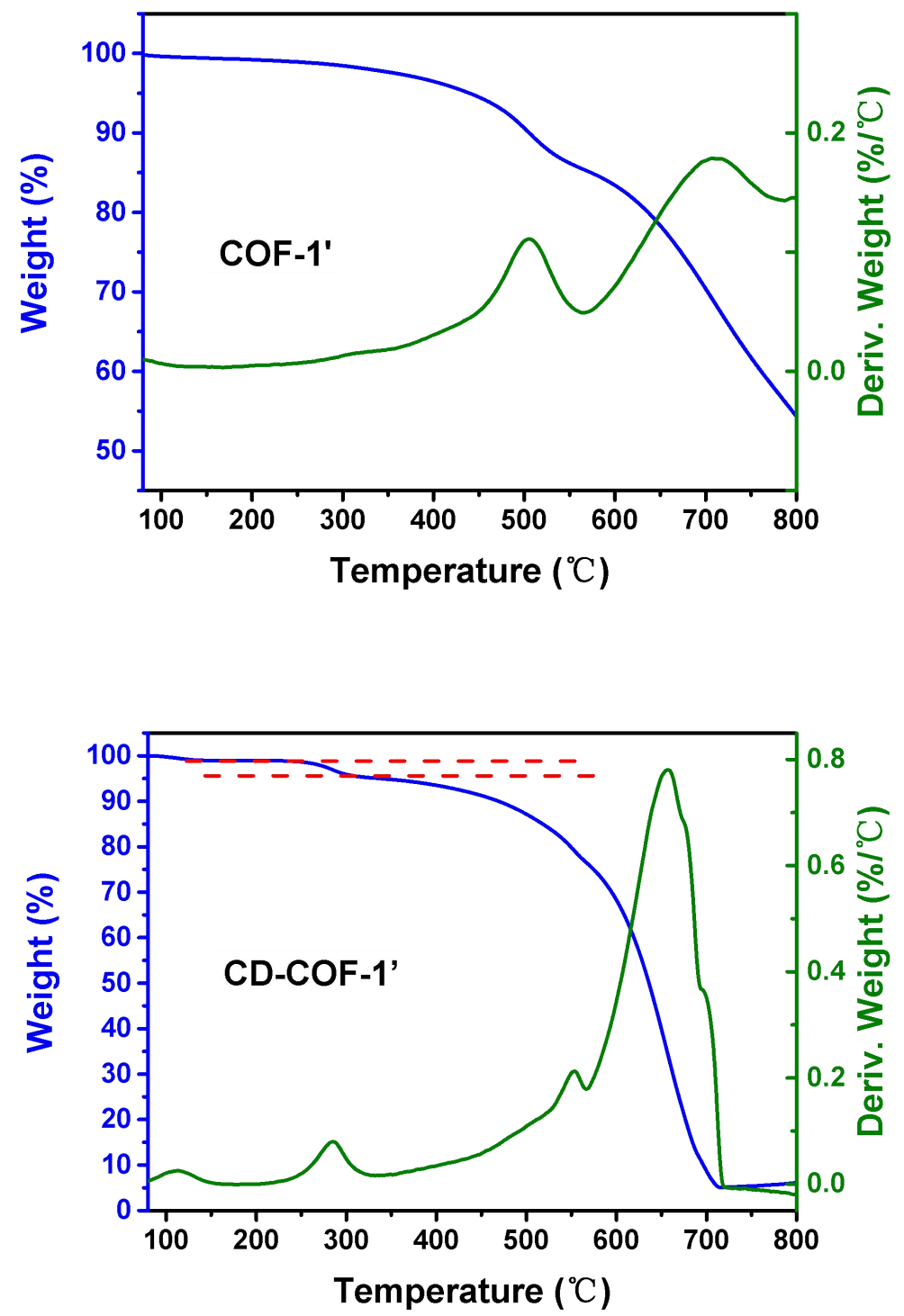
Figure S25. 'H NMR spectra of the digested COF-1' and CD-COF-1'.
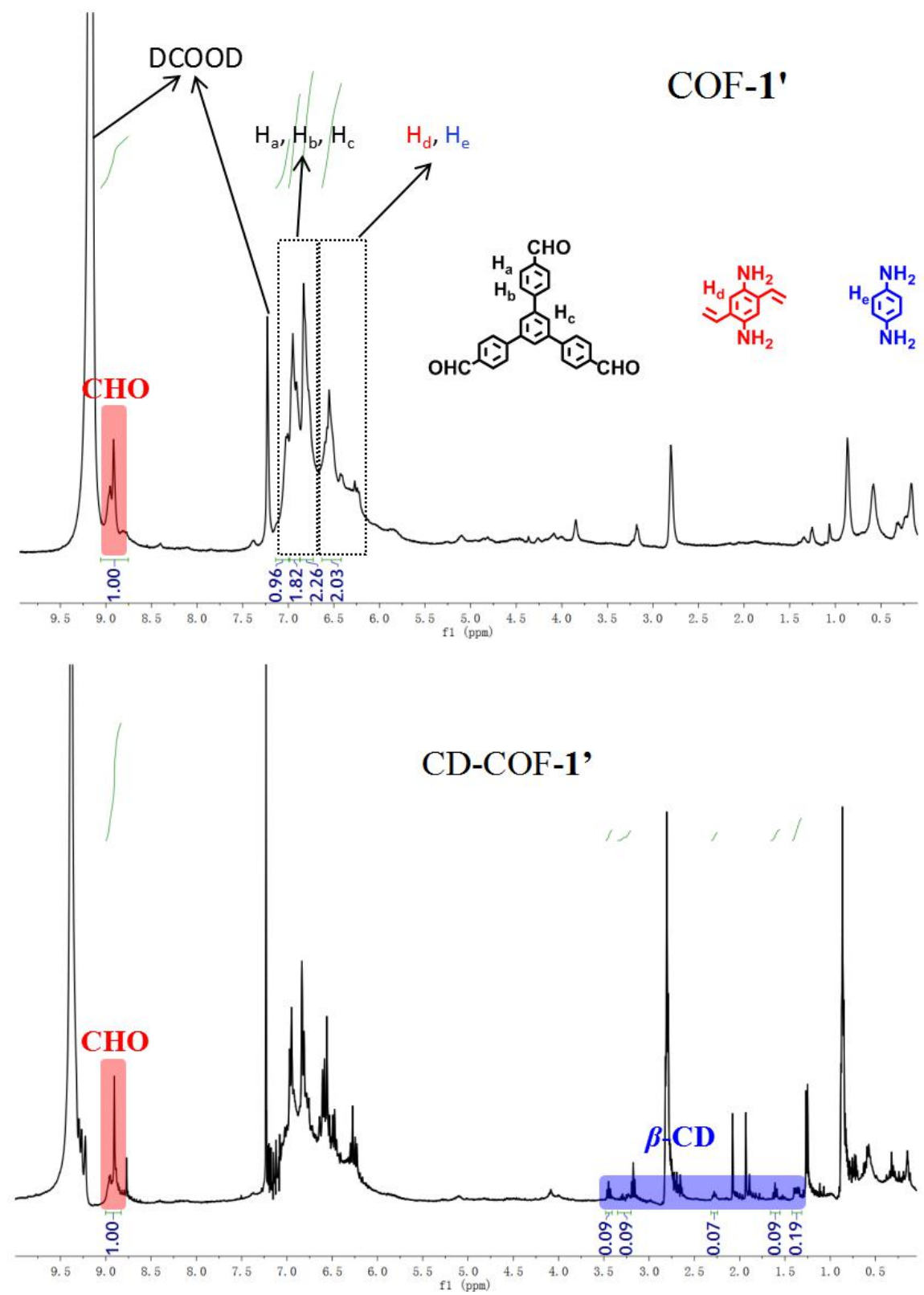
Figure S26. (a) $\mathrm{N}_{2}$ adsorption-desorption isotherms $(77 \mathrm{~K})$ and (b) pore size distribution profiles of COF-1' and CD-COF-1'.

a)
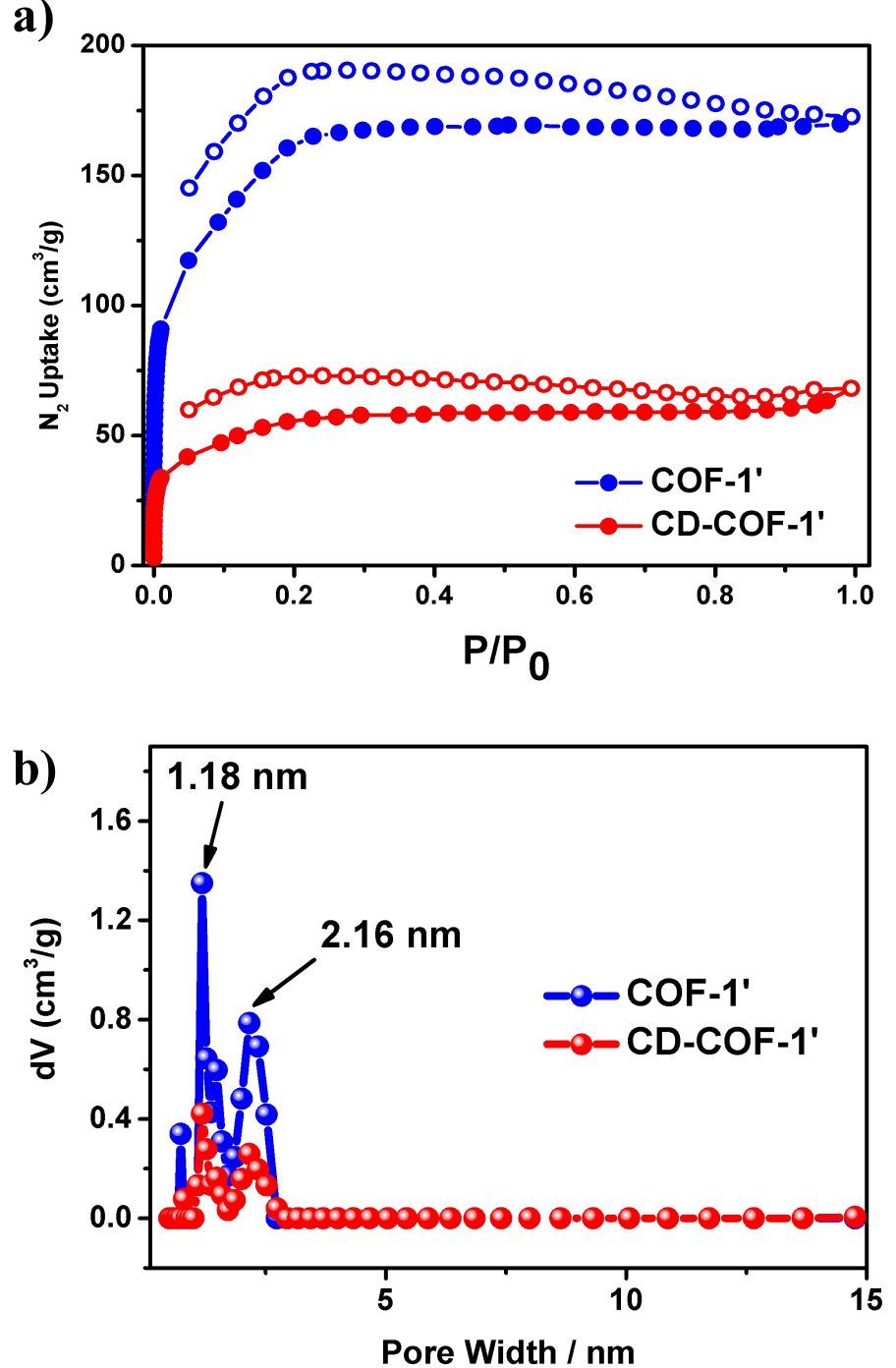
Figure S27. I-V characteristics of the CD-COF-1' MMM in 20 mM PBS (pH 7.2) with adding different concentrations of (a) $D$-His and (b) $L$-His $(0-1500 \mu \mathrm{M})$.
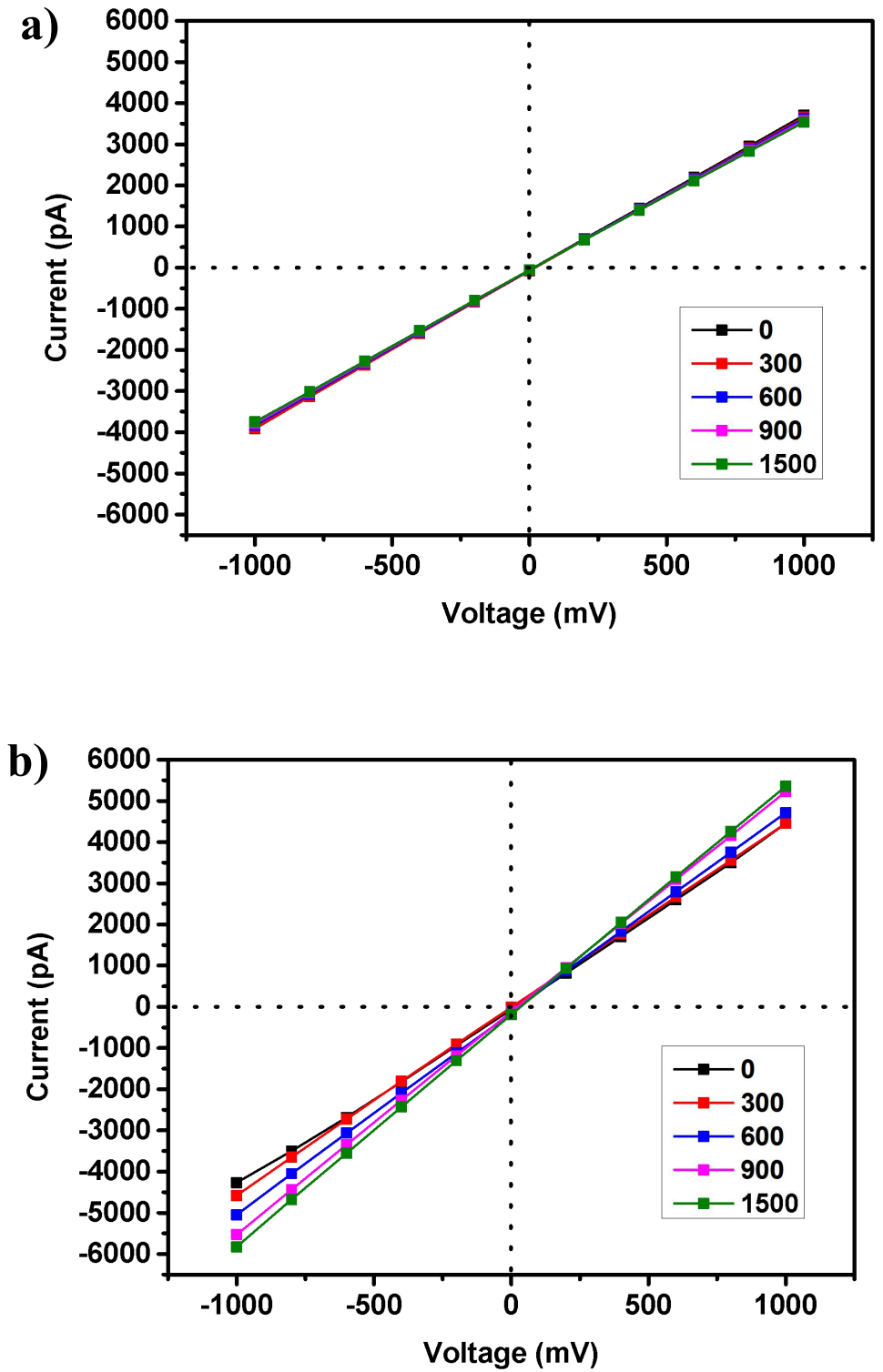
Figure S28. Effect of increasing concentrations of His on the current change ratios of CD-COF-1' MMM at -1 V.

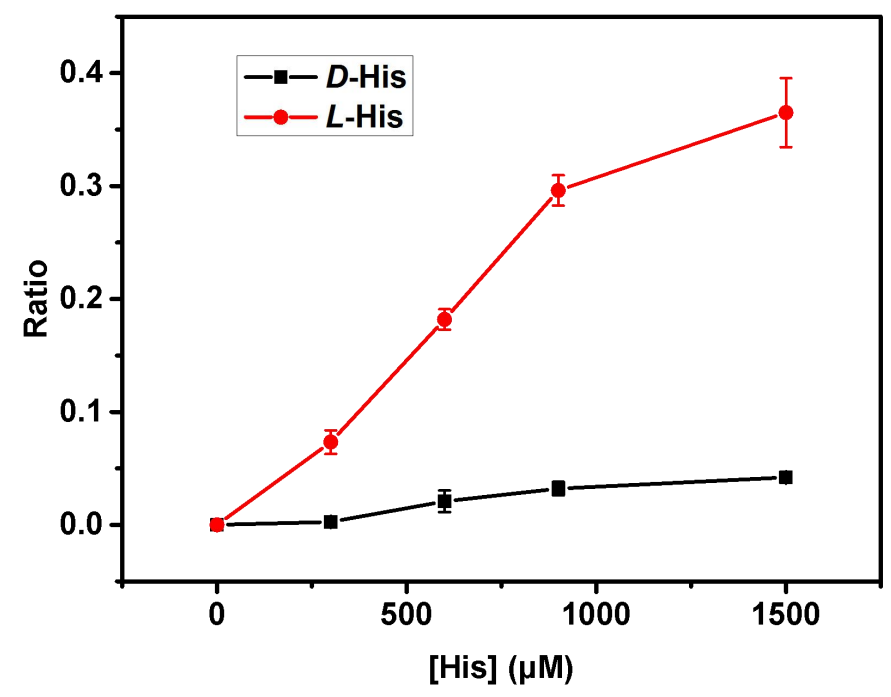


17. The reproducibility of MMMs.

Figure S29. Current change ratios of three separate CD-COF-1 MMMs in $20 \mathrm{mM}$ PBS (pH 7.2) containing $1500 \mu \mathrm{M} L$-His.

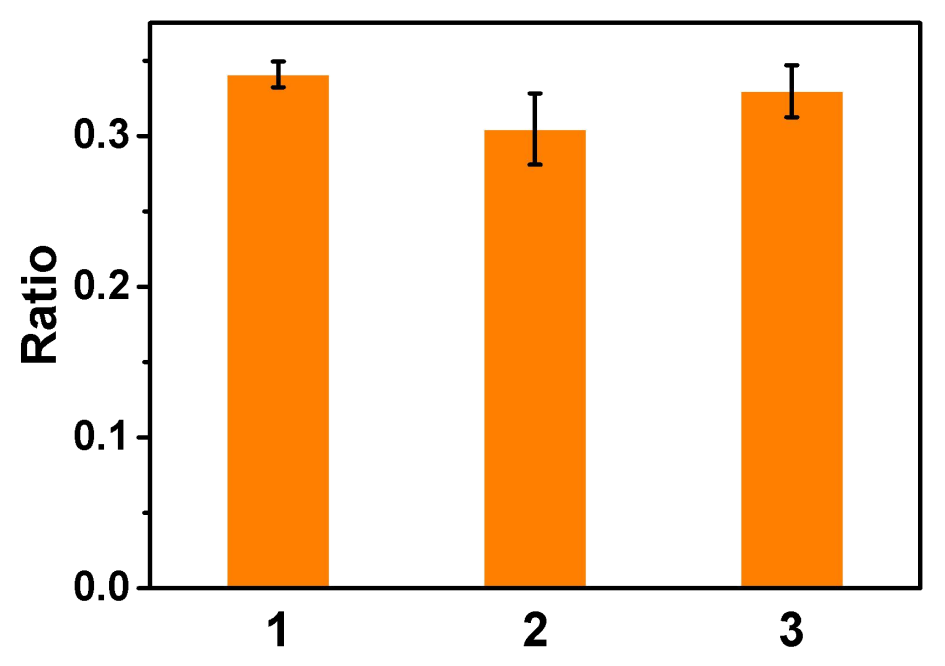

Figure S30. Current change ratios of regenerated CD-COF-1 MMMs in $20 \mathrm{mM}$ PBS (pH 7.2) containing $1500 \mu \mathrm{M} L$-His.

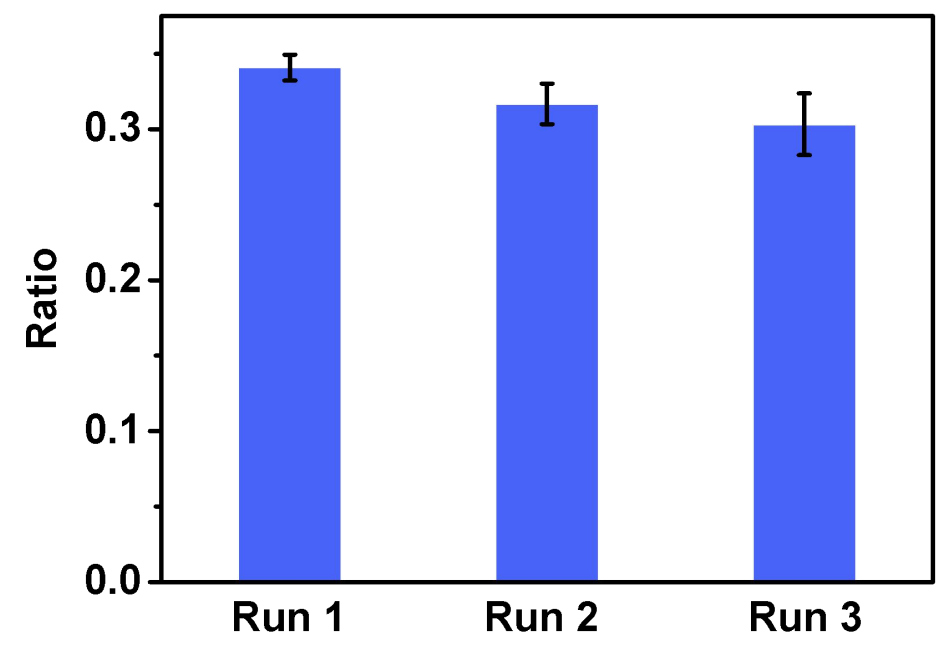




\section{Permeation experiment.}

The membranes with effective membrane area of $0.8 \mathrm{~cm}^{2}$ were fixed tightly in a cell at room temperature (Figure 6a). To one chamber of the cell, $15 \mathrm{~mL}$ of $5 \mathrm{mM}$ of amino acid buffer solution (20 mM PBS, pH 7.2) (2 mM for Tyr because of the solubility) was used as feed solution. For the other chamber, permeated solution was collected in different permeation time. The concentration of permeated solution was measured by high performance liquid chromatography (HPLC). Analytical high performance liquid chromatography (HPLC) experiments were performed on a Shimadzu HPLC system (Shimadzu Corporation, Kyoto, Japan) with UV detection at 200 nm. Optical resolution column (Crownpak CR(-), Daicel Chemical Industries, Ltd., Japan) and perchloric acid (pH 1.0) as mobile phase at flow rate $0.4 \mathrm{~mL} / \mathrm{min}$ are used for His, perchloric acid ( $\mathrm{pH} 2.0$ ) as mobile phase at flow rate $1.2 \mathrm{~mL} / \mathrm{min}$ are used for Trp. Standard curve in the range of 5-500 $\mu \mathrm{M}$ was created for $L$-His by using same HPLC condition, from which the concentrations of histidine ([His]) in the samples were determined by proportional to the HPLC peak area (Figure S31). The retention times of $L$-His, $D$-His, $L$-Trp, $D$-Trp, L-Tyr and D-Tyr are $3.7 \mathrm{~min}, 4.0 \mathrm{~min}$, $15.7 \mathrm{~min}, 18.8 \mathrm{~min}, 4.3 \mathrm{~min}$ and $5.4 \mathrm{~min}$ respectively.

Figure S31. Standard curve in the range of 5-500 $\mu \mathrm{M}$ for $L$-His.

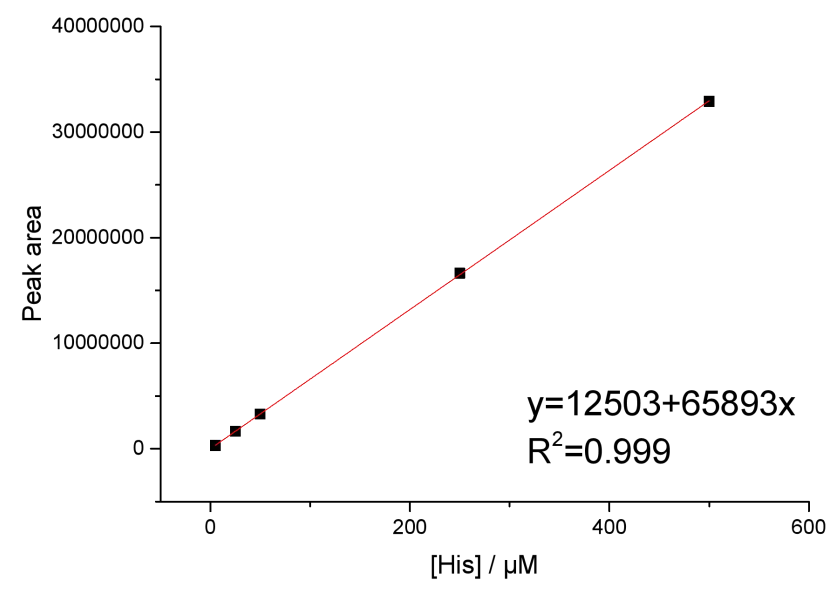


Figure S32. HPLC chromatograms for Trp and Tyr permeate solution after $36 \mathrm{~h}$ at $\mathrm{pH}$ 7.2 for CD-COF-1 MMM and CD-COF-2 MMM.
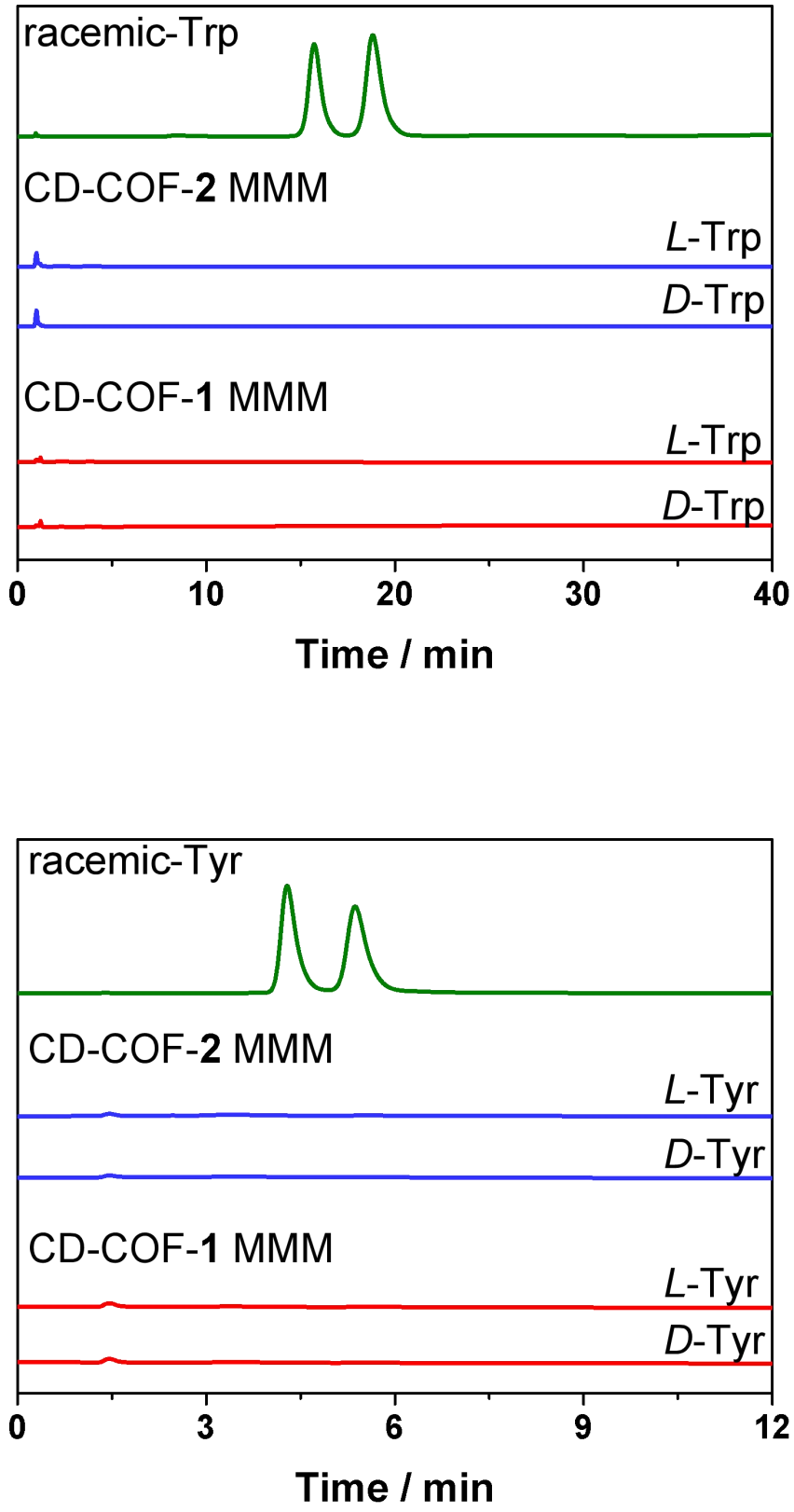
19. Fractional atomic coordinates and unit cell parameters.

Table S3. Fractional atomic coordinates of for the unit cell of diamond net COF-1 with $P 2$ space group.

\begin{tabular}{|c|c|c|c|}
\hline \multicolumn{4}{|c|}{$\begin{array}{l}\text { COF-1: Space group: } P 2 \\
a=36.21 \AA, b=36.61 \AA, c=3.74 \AA \\
\alpha=90.00^{\circ}, \beta=90.00^{\circ}, \gamma=115.64^{\circ}\end{array}$} \\
\hline Atom & $\mathrm{x}$ & $\mathrm{y}$ & $\mathrm{z}$ \\
\hline $\mathrm{C} 1$ & 1.39083 & 1.63719 & 2.40576 \\
\hline $\mathrm{C} 2$ & 1.43377 & 1.65835 & 2.31128 \\
\hline $\mathrm{C} 3$ & 1.45963 & 1.64071 & 2.3652 \\
\hline $\mathrm{C} 4$ & 1.44318 & 1.60134 & 2.50988 \\
\hline $\mathrm{C} 5$ & 1.40057 & 1.58026 & 2.61074 \\
\hline C6 & 1.37477 & 1.59805 & 2.56112 \\
\hline $\mathrm{C} 7$ & 1.47059 & 1.5825 & 2.54232 \\
\hline N8 & 1.45579 & 1.54548 & 2.6628 \\
\hline C9 & 1.47838 & 1.52281 & 2.69076 \\
\hline $\mathrm{C} 10$ & 1.45557 & 1.48011 & 2.70886 \\
\hline $\mathrm{C} 11$ & 1.52255 & 1.5423 & 2.70359 \\
\hline $\mathrm{C} 12$ & 1.36278 & 1.65513 & 2.32406 \\
\hline $\mathrm{C} 13$ & 1.37843 & 1.69737 & 2.33392 \\
\hline $\mathrm{C} 14$ & 1.37056 & 1.75954 & 2.23269 \\
\hline $\mathrm{C} 15$ & 1.34555 & 1.7769 & 2.34615 \\
\hline $\mathrm{C} 16$ & 1.36188 & 1.81901 & 2.3498 \\
\hline $\mathrm{C} 17$ & 1.40356 & 1.84468 & 2.24238 \\
\hline $\mathrm{C} 18$ & 1.42868 & 1.82749 & 2.12881 \\
\hline C19 & 1.4123 & 1.78537 & 2.1231 \\
\hline
\end{tabular}




\begin{tabular}{|c|c|c|c|}
\hline $\mathrm{C} 20$ & 1.42016 & 1.88907 & 2.25213 \\
\hline $\mathrm{N} 21$ & 1.45904 & 1.9136 & 2.1649 \\
\hline $\mathrm{C} 22$ & 1.47895 & 1.95718 & 2.16261 \\
\hline $\mathrm{C} 23$ & 1.52287 & 1.97887 & 2.15627 \\
\hline $\mathrm{C} 24$ & 1.45608 & 1.97871 & 2.15656 \\
\hline $\mathrm{C} 25$ & 1.35323 & 1.71473 & 2.22948 \\
\hline $\mathrm{C} 26$ & 1.31142 & 1.6892 & 2.12248 \\
\hline $\mathrm{C} 27$ & 1.24883 & 1.6198 & 2.04243 \\
\hline $\mathrm{C} 28$ & 1.23475 & 1.58093 & 1.88635 \\
\hline $\mathrm{C} 29$ & 1.19194 & 1.55484 & 1.83066 \\
\hline C30 & 1.16218 & 1.56705 & 1.92469 \\
\hline C31 & 1.176 & 1.60611 & 2.07151 \\
\hline C32 & 1.21874 & 1.63202 & 2.1323 \\
\hline C33 & 1.11706 & 1.53844 & 1.87486 \\
\hline N34 & 1.08887 & 1.54917 & 1.9572 \\
\hline $\mathrm{C} 35$ & 1.04414 & 1.52373 & 1.9389 \\
\hline C36 & 1.01865 & 1.5423 & 1.9418 \\
\hline C37 & 1.0251 & 1.48105 & 1.94124 \\
\hline C38 & 1.29424 & 1.64675 & 2.12828 \\
\hline C39 & 1.32046 & 1.63017 & 2.22555 \\
\hline $\mathrm{C} 40$ & 1.40883 & 1.45938 & 2.71137 \\
\hline $\mathrm{C} 41$ & 1.38488 & 1.42223 & 2.84864 \\
\hline $\mathrm{H} 42$ & 1.44726 & 1.688 & 2.18173 \\
\hline $\mathrm{H} 43$ & 1.49233 & 1.65745 & 2.28326 \\
\hline $\mathrm{H} 44$ & 1.38708 & 1.54996 & 2.72728 \\
\hline H45 & 1.34231 & 1.58107 & 2.64778 \\
\hline $\mathrm{H} 46$ & 1.50253 & 1.59935 & 2.4415 \\
\hline $\mathrm{H} 47$ & 1.53999 & 1.57501 & 2.70394 \\
\hline
\end{tabular}




\begin{tabular}{|c|c|c|c|}
\hline $\mathrm{H} 48$ & 1.41015 & 1.71687 & 2.43027 \\
\hline $\mathrm{H} 49$ & 1.31355 & 1.75797 & 2.43921 \\
\hline $\mathrm{H} 50$ & 1.34201 & 1.83158 & 2.44069 \\
\hline H51 & 1.46088 & 1.84652 & 2.04148 \\
\hline H52 & 1.43216 & 1.77303 & 2.02678 \\
\hline H53 & 1.39954 & 1.90066 & 2.34434 \\
\hline H54 & 1.54088 & 1.96274 & 2.15271 \\
\hline H55 & 1.42217 & 1.9632 & 2.14664 \\
\hline H56 & 1.29248 & 1.70257 & 2.02729 \\
\hline H57 & 1.25667 & 1.57057 & 1.8028 \\
\hline H58 & 1.18206 & 1.52503 & 1.71285 \\
\hline H59 & 1.15373 & 1.61631 & 2.14924 \\
\hline H60 & 1.22786 & 1.66108 & 2.26275 \\
\hline H61 & 1.10802 & 1.50845 & 1.76674 \\
\hline H62 & 1.03284 & 1.57509 & 1.94822 \\
\hline H63 & 1.04359 & 1.4655 & 1.95332 \\
\hline H64 & 1.30788 & 1.59765 & 2.22439 \\
\hline H65 & 1.39292 & 1.47537 & 2.6037 \\
\hline H66 & 1.35103 & 1.40922 & 2.84316 \\
\hline H67 & 1.39804 & 1.40479 & 2.97734 \\
\hline
\end{tabular}


Table S4. Fractional atomic coordinates of for the unit cell of diamond net COF-2 with $P 2{ }_{1}$ space group.

COF-2: Space group: $P 2_{1}$

$a=41.36 \AA, b=44.60 \AA, c=6.49 \AA$

$\alpha=90.00^{\circ}, \beta=90.00^{\circ}, \gamma=117.23^{\circ}$

\begin{tabular}{|c|c|c|c|}
\hline Atom & $\mathrm{x}$ & $\mathrm{y}$ & $\mathrm{z}$ \\
\hline $\mathrm{C} 1$ & 0.73015 & 0.36417 & -0.1167 \\
\hline $\mathrm{C} 2$ & 0.75148 & 0.35845 & 0.02981 \\
\hline $\mathrm{C} 3$ & 0.73189 & 0.3322 & 0.18031 \\
\hline N4 & 0.79307 & 0.37974 & 0.0237 \\
\hline $\mathrm{C} 5$ & 0.81587 & 0.36962 & 0.08551 \\
\hline C6 & 0.85821 & 0.39365 & 0.07022 \\
\hline $\mathrm{C} 7$ & 0.88173 & 0.38002 & 0.09311 \\
\hline $\mathrm{C} 8$ & 0.92192 & 0.40216 & 0.07856 \\
\hline $\mathrm{C} 9$ & 0.93981 & 0.43872 & 0.03993 \\
\hline $\mathrm{C} 10$ & 0.91564 & 0.452 & 0.01287 \\
\hline $\mathrm{C} 11$ & 0.87548 & 0.42986 & 0.03024 \\
\hline $\mathrm{C} 12$ & 0.98309 & 0.46269 & 0.02453 \\
\hline $\mathrm{C} 13$ & 1.00632 & 0.44914 & -0.02085 \\
\hline $\mathrm{C} 14$ & 1.19472 & 0.3315 & -0.08626 \\
\hline $\mathrm{C} 15$ & 1.16384 & 0.32193 & 0.04778 \\
\hline $\mathrm{C} 16$ & 1.1451 & 0.34036 & 0.04762 \\
\hline $\mathrm{C} 17$ & 1.15615 & 0.3688 & -0.08593 \\
\hline $\mathrm{C} 18$ & 1.18681 & 0.37916 & -0.22464 \\
\hline C19 & 1.20633 & 0.36148 & -0.22846 \\
\hline N20 & 1.13531 & 0.3863 & -0.07249 \\
\hline $\mathrm{C} 21$ & 1.14002 & 0.41246 & -0.18349 \\
\hline
\end{tabular}




\begin{tabular}{|c|c|c|c|}
\hline $\mathrm{C} 22$ & 1.11586 & 0.42731 & -0.14714 \\
\hline $\mathrm{C} 23$ & 1.12137 & 0.45565 & -0.26755 \\
\hline $\mathrm{C} 24$ & 1.09892 & 0.47017 & -0.23415 \\
\hline $\mathrm{C} 25$ & 1.07033 & 0.45635 & -0.08071 \\
\hline $\mathrm{C} 26$ & 1.06476 & 0.42794 & 0.03931 \\
\hline $\mathrm{C} 27$ & 1.08735 & 0.4136 & 0.00688 \\
\hline $\mathrm{C} 28$ & 1.04646 & 0.47155 & -0.04271 \\
\hline $\mathrm{C} 29$ & 1.06376 & 0.50824 & -0.02705 \\
\hline $\mathrm{C} 30$ & 1.20903 & 0.80889 & 0.13826 \\
\hline C31 & 1.22264 & 0.79266 & 0.00916 \\
\hline C32 & 1.20292 & 0.75584 & -0.00426 \\
\hline C33 & 1.16884 & 0.73451 & 0.10687 \\
\hline C34 & 1.15537 & 0.75047 & 0.23881 \\
\hline C35 & 1.17534 & 0.78731 & 0.25461 \\
\hline N36 & 1.14921 & 0.69683 & 0.08646 \\
\hline $\mathrm{C} 37$ & 1.11209 & 0.67489 & 0.10578 \\
\hline C38 & 1.0947 & 0.6365 & 0.08244 \\
\hline C39 & 1.05481 & 0.61423 & 0.05061 \\
\hline $\mathrm{C} 40$ & 1.03785 & 0.57783 & 0.02516 \\
\hline C41 & 1.06019 & 0.56239 & 0.0394 \\
\hline $\mathrm{C} 42$ & 1.10047 & 0.5853 & 0.07059 \\
\hline $\mathrm{C} 43$ & 1.11745 & 0.62178 & 0.09026 \\
\hline C44 & 1.04169 & 0.52296 & 0.0212 \\
\hline $\mathrm{C} 45$ & 1.00154 & 0.49955 & 0.05202 \\
\hline $\mathrm{C} 46$ & 0.75078 & 0.39255 & -0.27287 \\
\hline $\mathrm{C} 47$ & 0.73686 & 0.39108 & -0.45972 \\
\hline $\mathrm{C} 48$ & 1.69125 & 0.31081 & 0.18401 \\
\hline $\mathrm{C} 49$ & 1.66985 & 0.31551 & 0.0324 \\
\hline
\end{tabular}




\begin{tabular}{|l|l|l|l|}
\hline C50 & 1.6895 & 0.34282 & -0.11288 \\
\hline N51 & 1.62822 & 0.29296 & 0.03547 \\
\hline C52 & 1.60426 & 0.28967 & -0.10693 \\
\hline C53 & 1.56214 & 0.26518 & -0.07977 \\
\hline C54 & 1.53659 & 0.26555 & -0.22192 \\
\hline C55 & 1.4966 & 0.2425 & -0.19937 \\
\hline C56 & 1.48158 & 0.2183 & -0.03602 \\
\hline C57 & 1.5071 & 0.21779 & 0.10581 \\
\hline C58 & 1.54704 & 0.24119 & 0.08511 \\
\hline C59 & 1.43935 & 0.19337 & -0.01445 \\
\hline C60 & 1.41438 & 0.20581 & -0.01648 \\
\hline C61 & 1.21562 & 0.31271 & -0.08266 \\
\hline C62 & 1.2335 & 0.31003 & -0.25913 \\
\hline C63 & 1.25341 & 0.29262 & -0.25266 \\
\hline C64 & 1.25584 & 0.27695 & -0.07176 \\
\hline C65 & 1.23867 & 0.27936 & 0.10949 \\
\hline C66 & 1.21878 & 0.29666 & 0.10938 \\
\hline N67 & 1.27754 & 0.26021 & -0.07674 \\
\hline C68 & 1.27528 & 0.23749 & 0.05609 \\
\hline C69 & 1.3002 & 0.22305 & 0.03818 \\
\hline C70 & 1.29641 & 0.19804 & 0.18193 \\
\hline C71 & 1.32017 & 0.18448 & 0.17082 \\
\hline C72 & 1.34837 & 0.1959 & 0.01645 \\
\hline C73 & 1.35207 & 0.22082 & -0.12809 \\
\hline C74 & 1.32813 & 0.2342 & -0.11788 \\
\hline C75 & 1.37436 & 0.18235 & 0.00923 \\
\hline C76 & 1.35931 & 0.14601 & 0.0309 \\
\hline C77 & 1.22962 & -0.15188 & 0.14886 \\
\hline
\end{tabular}




\begin{tabular}{|c|c|c|c|}
\hline C78 & 1.2088 & -0.13522 & 0.16788 \\
\hline C79 & 1.2281 & -0.09832 & 0.17035 \\
\hline $\mathrm{C} 80$ & 1.26837 & -0.07732 & 0.14994 \\
\hline C81 & 1.28946 & -0.09379 & 0.13654 \\
\hline C82 & 1.27024 & -0.13067 & 0.13621 \\
\hline N83 & 1.28684 & -0.03952 & 0.14491 \\
\hline C84 & 1.31967 & -0.01777 & 0.05566 \\
\hline $\mathrm{C} 85$ & 1.33604 & 0.02071 & 0.05463 \\
\hline C86 & 1.36745 & 0.0425 & -0.07421 \\
\hline C87 & 1.38301 & 0.0789 & -0.08193 \\
\hline C88 & 1.36765 & 0.09435 & 0.04053 \\
\hline C89 & 1.33639 & 0.07252 & 0.17132 \\
\hline C90 & 1.32067 & 0.03603 & 0.17805 \\
\hline C91 & 1.38387 & 0.133 & 0.02852 \\
\hline C92 & 1.42398 & 0.15705 & 0.00918 \\
\hline C93 & 1.67078 & 0.28285 & 0.3426 \\
\hline C94 & 1.68461 & 0.2851 & 0.53055 \\
\hline H95 & 0.74842 & 0.32846 & 0.29502 \\
\hline H96 & 0.80411 & 0.34274 & 0.13923 \\
\hline H97 & 0.86901 & 0.3521 & 0.12368 \\
\hline H98 & 0.93858 & 0.39028 & 0.10343 \\
\hline H99 & 0.92726 & 0.4793 & -0.02774 \\
\hline H100 & 0.85795 & 0.44107 & 0.00964 \\
\hline H101 & 0.99356 & 0.42119 & -0.04715 \\
\hline H102 & 1.15365 & 0.29987 & 0.15231 \\
\hline H103 & 1.12144 & 0.33235 & 0.15383 \\
\hline H104 & 1.19635 & 0.40105 & -0.32913 \\
\hline H105 & 1.23048 & 0.37058 & -0.33235 \\
\hline
\end{tabular}




\begin{tabular}{|c|c|c|c|}
\hline H106 & 1.16138 & 0.42378 & -0.30419 \\
\hline H107 & 1.14307 & 0.4666 & -0.38746 \\
\hline H108 & 1.10363 & 0.49192 & -0.3296 \\
\hline H109 & 1.04324 & 0.41714 & 0.16034 \\
\hline H110 & 1.08248 & 0.39183 & 0.10281 \\
\hline H111 & 1.0945 & 0.52488 & -0.05394 \\
\hline H112 & 1.24814 & 0.8084 & -0.08473 \\
\hline H113 & 1.21375 & 0.74385 & -0.10527 \\
\hline H114 & 1.12985 & 0.73457 & 0.33224 \\
\hline H115 & 1.16461 & 0.79884 & 0.3597 \\
\hline H116 & 1.09318 & 0.68462 & 0.12954 \\
\hline H117 & 1.03678 & 0.62512 & 0.0403 \\
\hline H118 & 1.00733 & 0.56232 & -0.01036 \\
\hline H119 & 1.11936 & 0.57553 & 0.08577 \\
\hline H120 & 1.1484 & 0.63838 & 0.11528 \\
\hline H121 & 0.98458 & 0.50994 & 0.10252 \\
\hline H122 & 0.77935 & 0.41507 & -0.23742 \\
\hline H123 & 0.70935 & 0.36877 & -0.51011 \\
\hline H124 & 0.7537 & 0.41233 & -0.56775 \\
\hline H125 & 1.67339 & 0.34814 & -0.22113 \\
\hline H126 & 1.61449 & 0.30427 & -0.24907 \\
\hline H127 & 1.54757 & 0.28378 & -0.35026 \\
\hline H128 & 1.47739 & 0.24315 & -0.31117 \\
\hline H129 & 1.49606 & 0.19948 & 0.23375 \\
\hline H130 & 1.56605 & 0.24027 & 0.19706 \\
\hline H131 & 1.42629 & 0.23394 & -0.03132 \\
\hline H132 & 1.23193 & 0.32106 & -0.40366 \\
\hline H133 & 1.26707 & 0.29113 & -0.39118 \\
\hline
\end{tabular}




\begin{tabular}{|l|l|l|l|}
\hline H134 & 1.24129 & 0.26872 & 0.25304 \\
\hline H135 & 1.20677 & 0.29898 & 0.25179 \\
\hline H136 & 1.25472 & 0.22835 & 0.18116 \\
\hline H137 & 1.27523 & 0.18917 & 0.30407 \\
\hline H138 & 1.31705 & 0.16559 & 0.2854 \\
\hline H139 & 1.37337 & 0.22978 & -0.24963 \\
\hline H140 & 1.33168 & 0.25342 & -0.23123 \\
\hline H141 & 1.3283 & 0.12778 & 0.04363 \\
\hline H142 & 1.1775 & -0.15065 & 0.1759 \\
\hline H143 & 1.21153 & -0.086 & 0.18294 \\
\hline H144 & 1.32073 & -0.07831 & 0.12875 \\
\hline H145 & 1.28728 & -0.14257 & 0.12723 \\
\hline H146 & 1.33457 & -0.02773 & -0.02981 \\
\hline H147 & 1.37963 & 0.03126 & -0.17145 \\
\hline H148 & 1.40664 & 0.09486 & -0.18685 \\
\hline H149 & 1.32428 & 0.08367 & 0.26976 \\
\hline H150 & 1.29662 & 0.01988 & 0.28024 \\
\hline H151 & 1.44337 & 0.267093 \\
\hline H152 & 1.6424 & 0.30776 & 0.64059 \\
\hline H153 & 1.66787 & 0.57977 \\
\hline H154 & 1.71191 & 0.2606 \\
\hline
\end{tabular}




\section{References.}

(1) Ishibashi, J. S. A.; Marshall, J. L.; Mazière, A.; Lovinger, G. J.; Li, B.; Zakharov, L. N.; Dargelos, A.; Graciaa, A.; Chrostowska, A.; Liu, S. Y. Two BN Isosteres of Anthracene: Synthesis and Characterization. J. Am. Chem. Soc. 2014, 136, 15414.

(2) Martinelli, J.; Thangavel, K.; Tei, L.; Botta, M. Dendrimeric $\beta$-Cyclodextrin/Gd ${ }^{\text {III }}$ Chelate Supramolecular Host-Guest Adducts as High-Relaxivity Mri Probes. Chem. Eur. J. 2014, 20, 10944. 